\title{
The transient atmospheric response to midlatitude SST anomalies
}

Article

Published Version

Ferreira, D. and Frankignoul, C. (2005) The transient atmospheric response to midlatitude SST anomalies. Journal of Climate, 18 (7). pp. 1049-1067. ISSN 1520-0442 doi: https://doi.org/10.1175/JCLI-3313.1 Available at https://centaur.reading.ac.uk/34262/

It is advisable to refer to the publisher's version if you intend to cite from the work. See Guidance on citing.

Published version at: http://dx.doi.org/10.1175/JCLI-3313.1

To link to this article DOI: http://dx.doi.org/10.1175/JCLI-3313.1

Publisher: American Meteorological Society

All outputs in CentAUR are protected by Intellectual Property Rights law, including copyright law. Copyright and IPR is retained by the creators or other copyright holders. Terms and conditions for use of this material are defined in the End User Agreement.

\section{www.reading.ac.uk/centaur}

\section{CentAUR}

Central Archive at the University of Reading

Reading's research outputs online 


\title{
The Transient Atmospheric Response to Midlatitude SST Anomalies
}

\author{
DAVID FERREIRA \\ Department of Earth, Atmospheric, and Planetary Sciences, Massachusetts Institute of Technology, Cambridge, Massachusetts \\ Claude Frankignoul \\ Université Pierre et Marie Curie IPSL/Laboratoire d'Océanographie Dynamique et de Climatologie, Paris, France
}

(Manuscript received 22 April 2004, in final form 20 August 2004)

\begin{abstract}
To study the transient atmospheric response to midlatitude SST anomalies, a three-layer quasigeostrophic (QG) model coupled to a slab oceanic mixed layer in the North Atlantic is used. As diagnosed from a coupled run in perpetual winter conditions, the first two modes of SST variability are linked to the model North Atlantic Oscillation (NAO) and eastern Atlantic pattern (EAP), respectively, the dominant atmospheric modes in the Atlantic sector. The two SST anomaly patterns are then prescribed as fixed anomalous boundary conditions for the model atmosphere, and its transient responses are established from a large ensemble of simulations.

In both cases, the tendency of the air-sea heat fluxes to damp the SST anomalies results in an anomalous diabatic heating of the atmosphere that, in turn, forces a baroclinic response, as predicted by linear theory. This initial response rapidly modifies the transient eddy activity and thus the convergence of eddy momentum and heat fluxes. The latter transforms the baroclinic response into a growing barotropic one that resembles the atmospheric mode that had created the SST anomaly in the coupled run and is thus associated with a positive feedback. The total adjustment time is as long as 3-4 months for the NAO-like response and 1-2 months for the EAP-like one. The positive feedback, in both cases, is dependent on the polarity of the SST anomaly, but is stronger in the NAO case, thereby contributing to its predominance at low frequency in the coupled system. However, the feedback is too weak to lead to an instability of the atmospheric modes and primarily results in an increase of their amplitude and persistence and a weakening of the heat flux damping of the SST anomaly.
\end{abstract}

\section{Introduction}

In the extratropics, the air-sea interactions are dominated by the forcing of the ocean by the natural variability of the atmosphere (Frankignoul and Hasselmann 1977). The large-scale extratropical sea surface temperature (SST) anomalies are primarily forced by anomalous latent and sensible heat fluxes resulting from changes in the surface atmospheric conditions (wind speed, air temperature, and humidity), although advection by Ekman currents and entrainment can also play a significant role, particularly at high latitudes (Frankignoul 1985; Cayan 1992b). It has been more difficult to establish whether the extratropical SST anomalies have a significant influence on the atmosphere. Determining such a feedback from observations has been hindered by the difficulty to separate causes and ef-

Corresponding author address: Dr. David Ferreira, Department of Earth, Atmospheric, and Planetary Sciences, Massachusetts Institute of Technology, Rm. 54-1515, 77 Massachusetts Ave., Cambridge, MA 02139.

E-mail: dfer@mit.edu fects. However, using sophisticated statistical methods, Czaja and Frankignoul (1999) showed that North Atlantic SST anomalies could significantly influence the extratropical atmosphere during certain seasons. In particular, the wintertime North Atlantic Oscillation (NAO) was related to a basin-scale SST anomaly during the preceding summer. Although one has to be cautious interpreting correlations, the signal could explain about $15 \%$ of the monthly variance of the wintertime NAO (Czaja and Frankignoul 2002).

Similarly, it is only recently that a consistent picture has begun to emerge from sensitivity studies with atmospheric general circulation models (AGCMs). The early experiments showed much disparity in the atmospheric response. The modeled response to extratropical SST anomalies could be baroclinic (Kushnir and Held 1996; Peng et al. 1997, their January case) or equivalent barotropic (Palmer and Sun 1985; Peng et al. 1997, their February case) and its sensitivity to the amplitude and polarity of the SST anomaly also varied considerably. Nonetheless, as reviewed by Kushnir et al. (2002), recent studies suggest that there is an equivalent barotropic response with a ridge (trough) some- 
what downstream of a warm (cold) SST anomaly and they underscore the critical role of transient eddies (fluctuations with periods of about 2-8 days) in shaping such a response (Peng and Whitaker 1999; Hall et al. 2001a,b).

In the absence of transient eddies (linear dynamics) or in case of an underestimated eddy activity, a baroclinic response is predicted with a shallow trough and an upper-level ridge downstream of a warm SST (Hoskins and Karoly 1981). However, an equivalent barotropic response prevails if the eddy feedback is realistically simulated, consistent with the observations. Using a combination of a linear model and a storm track model, Peng and Whitaker (1999) found that the large-scale baroclinic response to the SST-induced heating can modify the storm track and thus the eddy momentum fluxes in such a way that they reinforce the upper-level response and reverse the low-level one, thus transforming the baroclinic structure into an equivalent barotropic one (their February case). This relationship between transient eddies and low-frequency fluctuations is an observed characteristic of the extratropical atmosphere (Lau and Nath 1991). However, for a January climatological state, Peng and Whitaker found a dramatically different transient eddy feedback (although the linear response was unchanged) leading to a baroclinic response. The strong influence of the transient eddies would then explain the dependence of the atmospheric response on the climatological flow as observed by Peng et al. (1997). By the same token, the atmospheric response depends on the location of the SST anomaly with respect to the storm track (Walter et al. 2001) and its dependence on the location of the SST anomaly relative to the dominant modes of variability (Peng and Robinson 2001) may only reflect the strong two-way feedback between the low-frequency atmospheric variability and the transient eddies (Branstator 1995). This suggests that sensitivity studies with AGCMs should be based on SST anomalies that are fully consistent with the model dynamics, for example, as determined from a coupled ocean-atmosphere run as in the present study.

Most of the AGCM sensitivity studies deal with the equilibrium response of the atmosphere. Kushnir and Lau (1992) made a first attempt at investigating the transient atmospheric response to a prescribed SST anomaly, and observed a slow atmospheric adjustment, maybe as long as 3 months. This is much longer than usually assumed (around 10 days), but because of the limited number of simulations, their results were only marginally significant. In addition, they relied on 3-month averages and could not obtain a detailed picture of the evolution. Hall et al. (2001b) investigated the transient response to a prescribed diabatic heating using monthly averages and also found a slow adjustment. Recently, Li and Conil (2003) studied the transient response of an AGCM to a prescribed SST anomaly over 8 days. They observed an initial baro- clinic response and a tendency toward an equivalent barotropic response. However, they could not address the full evolution to equilibrium.

In the present paper, we establish in more detail the successive steps and associated time scales that lead to the equilibrium atmospheric response to a prescribed SST anomaly. Complementing the work of Peng and Whitaker (1999) and others, we also aim at documenting the role played by transient eddy heat and momentum fluxes. In addition, we quantify the feedbacks resulting from the atmospheric response. To focus on the establishment of the equilibrium response, we discard the seasonal cycle and concentrate on the wintertime when air-sea exchanges are maximum.

Contrary to most previous studies, we base our work on both a (simplified) AGCM and its coupling to a simple ocean model. This allows us to prescribe SST anomalies that are fully consistent with the modeled atmospheric variability and to discuss to what extent the sensitivity experiments are actually relevant to the coupled system. Our focus is on the extratropical Atlantic Ocean. As the atmospheric response to extratropical SST is weak compared to the natural variability, the signal-to-noise ratio is low and extensive ensemble integrations are required. Therefore, we built a coupled ocean-atmosphere model of intermediate complexity composed of a three-layer quasigeostrophic (QG) atmosphere and a slab oceanic mixed layer in the North Atlantic. The model is computationally efficient and simulates rather realistically the dominant features of the Northern Hemisphere wintertime climate. The model and the reference coupled and uncoupled runs are described in section 2 . The transient atmospheric response to the leading mode of simulated SST variability is considered in section 3. Section 4 gives a brief account of the response to the second mode of SST variability. A discussion and conclusions are given in section 5.

\section{A coupled model of intermediate complexity}

\section{a. The coupled model}

The atmospheric component is derived from Marshall and Molteni's (1993) three-layer QG spectral model. It has a realistic geometry (land-sea mask and topography). The prognostic variable is the QG potential vorticity $(\mathrm{PV}) q$ :

$$
\frac{\partial q}{\partial t}=-J(\psi, q)-\frac{f_{o} R}{C_{\mathrm{pa}}} \frac{\partial}{\partial p}\left(\frac{Q}{p \sigma}\right)-D(\psi)+S
$$

with

$$
q=\nabla^{2} \psi+f+\frac{\partial}{\partial p}\left(\frac{f_{o}^{2}}{\sigma} \frac{\partial \psi}{\partial p}\right)
$$

which is solved, in T31 resolution, at the pressure levels 800,500 , and $200 \mathrm{mb}$. Here, $\psi$ is the geostrophic stream- 
function, $J$ is the Jacobian, $f$ is the Coriolis parameter, and $f_{o}$ is a reference value at $45^{\circ} \mathrm{N}, \sigma$ is the static stability, $R$ is the gas constant, $C_{\mathrm{pa}}$ is the air specific heat at constant pressure, $Q$ is the diabatic heating, and $S$ is a constant source of potential vorticity introduced in order to have a realistic wintertime climatology (see below). Linear damping processes $D$ include a Newtonian relaxation of temperature with a 25-day time scale, an Ekman friction at $800 \mathrm{mb}$ (the drag coefficient depending on the land-sea contrast and the topographic height), and a scale-selective diffusion $\left(\nabla^{6}\right)$ of temperature and vorticity.

In contrast to Marshall and Molteni (1993), we explicitly represent the diabatic heating $Q$ resulting from air-sea heat exchanges, but only over the North Atlantic between $20^{\circ}$ and $60^{\circ} \mathrm{N}$. Since the SST-induced diabatic heating in the extratropics is shallow, with more than $90 \%$ of the energy released below $500 \mathrm{mb}$ (e.g., Kushnir and Held 1996; Peng and Whitaker 1999), it is assumed that the surface turbulent (latent plus sensible) heat flux $F$ is released locally in the lower layer. Then, the diabatic heating, resolved at the intermediate levels at 650 and $350 \mathrm{mb}$, is given by $Q_{650}=\left(\mathrm{g} / \Delta_{p}\right) F$ and $Q_{350}=0$, where $g / \Delta_{p}\left(\Delta_{p}=450 \mathrm{mb}\right)$ is a measure of the lower-layer thickness. Since water vapor is not a variable of our atmospheric model, this implicitly assumes that the latent flux is precipitated locally, consistent with AGCM results (e.g., Rodwell et al. 1999).

The oceanic component consists of a slab mixed layer in the North Atlantic between $20^{\circ}$ and $60^{\circ} \mathrm{N}$. Its depth $H_{o}$ is a function of space only and is prescribed from the December-February (DJF) climatology of Levitus and Boyer (1994). The SST $T$ is driven, on the atmospheric model Gaussian grid, by turbulent heat flux $F$ and the advection by Ekman currents, and is given by

$$
\frac{\partial T}{\partial t}=-\frac{F}{\rho_{O} C_{\mathrm{po}} H_{o}}+\frac{\mathbf{k} \times \boldsymbol{\tau} \cdot \nabla T}{\rho_{o} f_{o} H_{o}}+v \nabla^{2} T+S_{T},
$$

where $\tau$ is the surface wind stress, $\rho_{o}$ is the water density, $C_{\mathrm{po}}$ is the specific heat of ocean water, and $v(=2$ $\left.\times 10^{-3} \mathrm{~m}^{2} \mathrm{~s}^{-1}\right)$ is the coefficient of diffusivity. The time-independent forcing $S_{T}$ is added in order to achieve a realistic SST climatology.

The sensible surface flux is given by the bulk formula:

$$
F_{s}=\rho_{a} C_{H} C_{\mathrm{pa}}\left|\mathbf{U}_{s}\right|\left(T-T_{s}\right)
$$

where $\rho_{a}$ is the surface air density, and $C_{H}(=1.5 \times$ $\left.10^{-3}\right)$ is the drag coefficient, $\mathbf{U}_{s}$ is the surface wind chosen to be half of the $800-\mathrm{mb}$ wind, and $T_{s}$ is the surface air temperature. The latter is assumed to be linearly related to the $650-\mathrm{mb}$ temperature (or equally to the difference between the $800-$ and $500-\mathrm{mb}$ geostrophic streamfunction), as estimated from the geostrophic streamfunction and the surface air temperature of the 15-yr European Centre for Medium-Range
Weather Forecasts (ECMWF) Re-Analysis (ERA-15) for DJF between 1978 and 1994.

To obtain the latent heat flux, we prescribe a Bowen ratio $B=F_{s} / F_{l}$, consistent with the high correlation ( $\geq 0.8$ ) found by Cayan (1992a) between the monthly anomalies of latent and sensible heat fluxes over most of the North Atlantic basin. Hence, the total surface heat flux takes the following form:

$$
F=F_{s}+F_{l}=\rho_{a} C_{H} C_{\mathrm{pa}}\left(1+B^{-1}\right)\left|\mathbf{U}_{s}\right|\left(T-T_{s}\right) .
$$

Estimation of $B$ from observations shows that it varies mainly with latitude, ranging from about 0.1 in the Tropics to about 1 at high latitudes (Cayan 1992a). Hence, we prescribe $B^{-1}$ as a third-order polynomial of the latitude smoothly varying from 7 at $20^{\circ} \mathrm{N}$ to 1 at $60^{\circ} \mathrm{N}$. The wind stress in (3) is computed by the following bulk formula:

$$
\tau=\rho_{a} C_{E}\left|\mathbf{U}_{s}\right| \mathbf{U}_{s},
$$

with $C_{E}$ equal to $2 \times 10^{-3}$.

Finally, the time-independent forcings $S$ and $S_{T}$ are empirically derived as in Marshall and Molteni (1993), but the method is extended here to a coupled model. In the atmosphere, the forcing $S$ is a spatially varying source of potential vorticity that corrects for the mean effects of neglected processes (e.g., the divergent flow, radiative forcing, and diabatic heating outside the North Atlantic), using observed values of the geostrophic streamfunction and the North Atlantic SST [twice-daily ERA-15 of the streamfunction for DJF between 1978 and 1994, denoted $\left(\hat{\psi}_{j}\right)$, and the DJF climatological mean SST $\hat{T}$ over the same period from the Comprehensive OceanAtmosphere Data Set (COADS)]. In practice, for each observation inserted in the model equation, a residual is computed. Assuming the long-term tendency of the observed state to be negligible, $S$ is equal to the averaged residual. If (1) is written as

$$
\frac{\partial q}{\partial t}=N(\psi)+Q(T, \psi)+S
$$

and $S$ is computed as

$$
S=-\overline{N\left(\hat{\psi}_{j}\right)}-\overline{Q\left(\hat{T}, \hat{\psi}_{j}\right)}
$$

where an overbar denotes an average over all observations, it can be interpreted as the forcing that makes the observed atmosphere a mean steady solution of the model.

A similar idea is applied to the SST equation written as

$$
\frac{\partial T}{\partial t}=F_{\mathrm{atm}}(T, \psi)+D(T)+S_{T}
$$

First, a 500-month atmospheric simulation with $\hat{T}$ prescribed as a fixed boundary condition is performed. The last 100 months are saved twice daily, and used as a new 


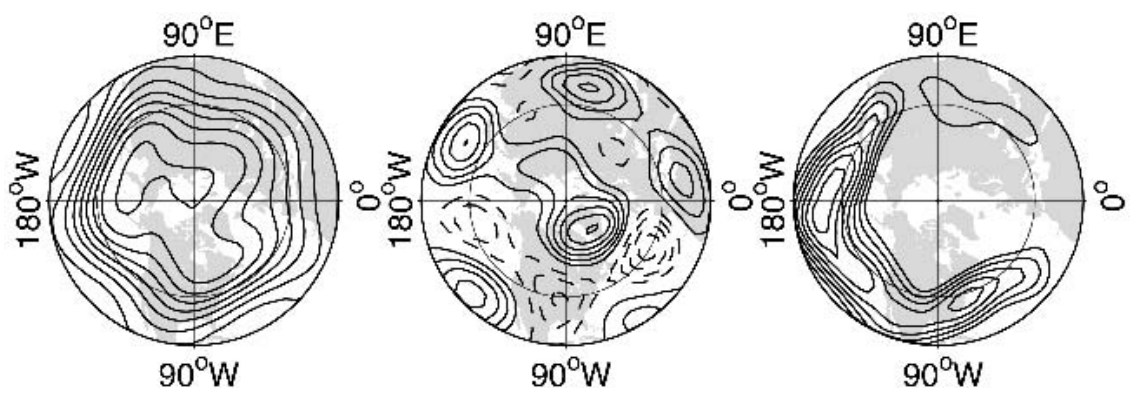

FIG. 1. (left) Mean geopotential height at $500 \mathrm{mb}$ (contour interval is $100 \mathrm{~m}$ ). (middle) Difference between the model and the ECMWF DJF climatology (contour interval is $30 \mathrm{~m}$, negative contours are dashed, and the zero contour is omitted). (right) Transient eddy variability defined as the rms of the geopotential height fluctuations with periods between 2 and 6.5 days (contour interval is $5 \mathrm{~m}$ for values above $35 \mathrm{~m}$ ). Latitudes extend down to $20^{\circ} \mathrm{N}$ and the latitude circle at $40^{\circ} \mathrm{N}$ is indicated.

set of atmospheric observations $\left(\tilde{\psi}_{j}\right)$ from which we compute $S_{T}$ by

$$
S_{T}=-\overline{F_{\text {atm }}\left(\hat{T}, \tilde{\psi}_{j}\right)}-\overline{D(\hat{T})} .
$$

Using the model streamfunction $\left(\tilde{\psi}_{j}\right)$ instead of the observed one $\left(\hat{\psi}_{j}\right)$ allows us to take into account the biases of the atmospheric model when determining $S_{T}$. As expected, $S_{T}$ is found to have a maximum along the Gulf Stream path, which mimics the mean heat flux convergence due to neglected geostrophic ocean currents.

\section{b. The coupled run}

After a 100-month spinup, the coupled model was in a statistically steady state and run for 1000 months with no discernible trend. In the following, we only consider the Northern Hemisphere. Considering the simplicity of the model, the climatology and variability of both the atmosphere and the North Atlantic SST are satisfactory. As illustrated in Fig. 1, the mean streamfunction (left) at $500 \mathrm{mb}$ is well reproduced, and the jet maxima in the western part of the Pacific and Atlantic basins well defined, albeit too zonal and shifted a few degrees southward. The North Atlantic jet is also too divergent as shown by the mean error in geopotential height (middle), which reaches its absolute maximum of about $180 \mathrm{~m}$ at $500 \mathrm{mb}$. This only a little larger than in many AGCMs (D'Andrea et al. 1998). Hall et al. (2001b) used a similar model solving the primitive equations at 10 vertical levels and found a maximum error of $100 \mathrm{~m}$ at $500 \mathrm{mb}$.

As in the observations, the transient eddy variability (right), defined as the rms of the geopotential height fluctuations with periods ranging between 2 and 6.5 days (filter from Blackmon 1976), is characterized by two maxima (storm tracks), albeit not separated enough. In the Atlantic, the rms value reaches $55 \mathrm{~m}$ at $500 \mathrm{mb}$ compared to $60 \mathrm{~m}$ in the observations. This represents a significant improvement relative to the T21 version of the model used by Marshall and Molteni
(1993) that underestimated the storm track intensity by $25 \%$. Also, the observed transient eddy feedback on the low-frequency variability is well reproduced (not shown). Consistent with Lau and Nath (1991), the lowfrequency anomalies (which are equivalent barotropic) generate storm track anomalies. The resulting anomalous eddy momentum flux convergence sustains the low-frequency anomalies throughout the air column while the eddy anomalous heat flux convergence sustains them at $800 \mathrm{mb}$ and damps them above. The total effect is a positive feedback on the barotropic component with a negative feedback on the baroclinic one (barotropization effect).

The simulated SST climatology (not shown) is quite realistic with a maximum error of $0.6 \mathrm{~K}$ compared to the COADS DJF climatology $\hat{T}$. However, the variability (monthly mean rms) is underestimated by a factor of 2 , although it reproduces the observed maximum along the western boundary around $40^{\circ} \mathrm{N}$. This can be attributed to the neglect of entrainment, geostrophic advection, and other mixed layer dynamics.

The principal modes of low-frequency variability in the North Atlantic sector $\left(15^{\circ}-75^{\circ} \mathrm{N}, 90^{\circ} \mathrm{W}-10^{\circ} \mathrm{E}\right)$ were determined by an empirical orthogonal function (EOF) analysis using monthly (30 days) means and a weighting by the square root of the cosine of the latitude. The first two EOFs of the 500-mb geopotential height (hereafter Z500) projected onto the whole Northern Hemisphere are shown in Fig. 2 (left). The first mode is very similar to the NAO, the dominant mode in winter (Wallace and Gutzler 1981). Although the largest amplitude is found in the Atlantic, the pattern is hemispheric in extent and resembles the Arctic Oscillation, which is a bias of this atmospheric model (e.g., D'Andrea and Vautard 2001). The second mode is a monopole centered south of Greenland that bears some resemblance to the eastern Atlantic pattern (EAP; Wallace and Gutzler 1981). The first two SST EOFs (right) capture about $75 \%$ of the variability. The first EOF is primarily a midlatitude dipole and the second one is a monopole 


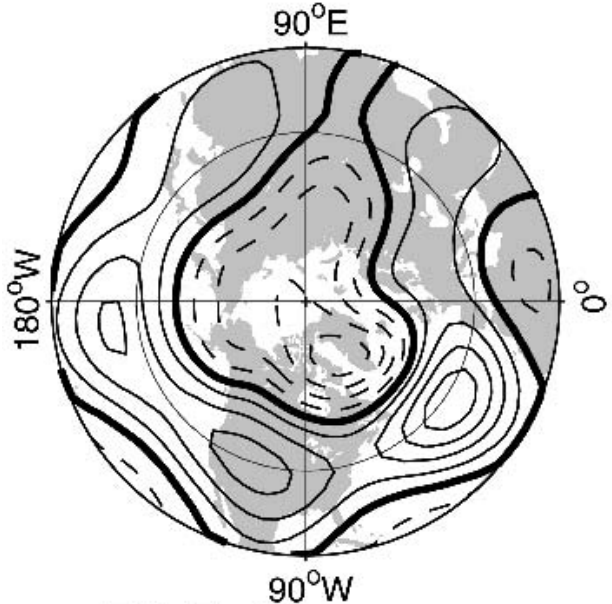

EOF1 Z500 47\%

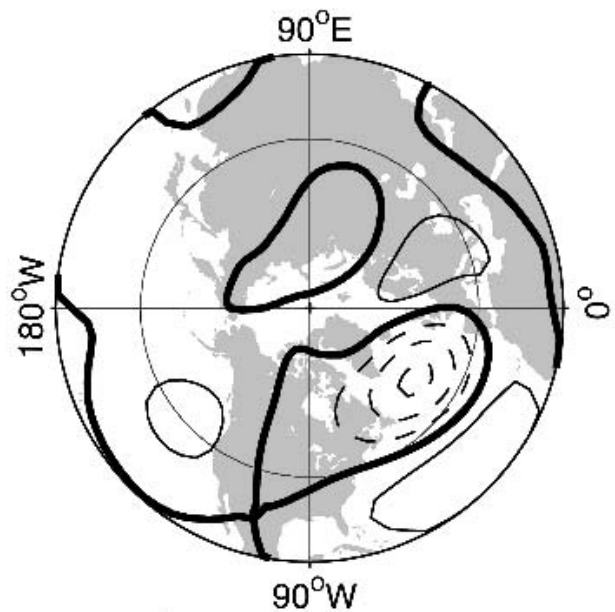

EOF2 Z500 16\%
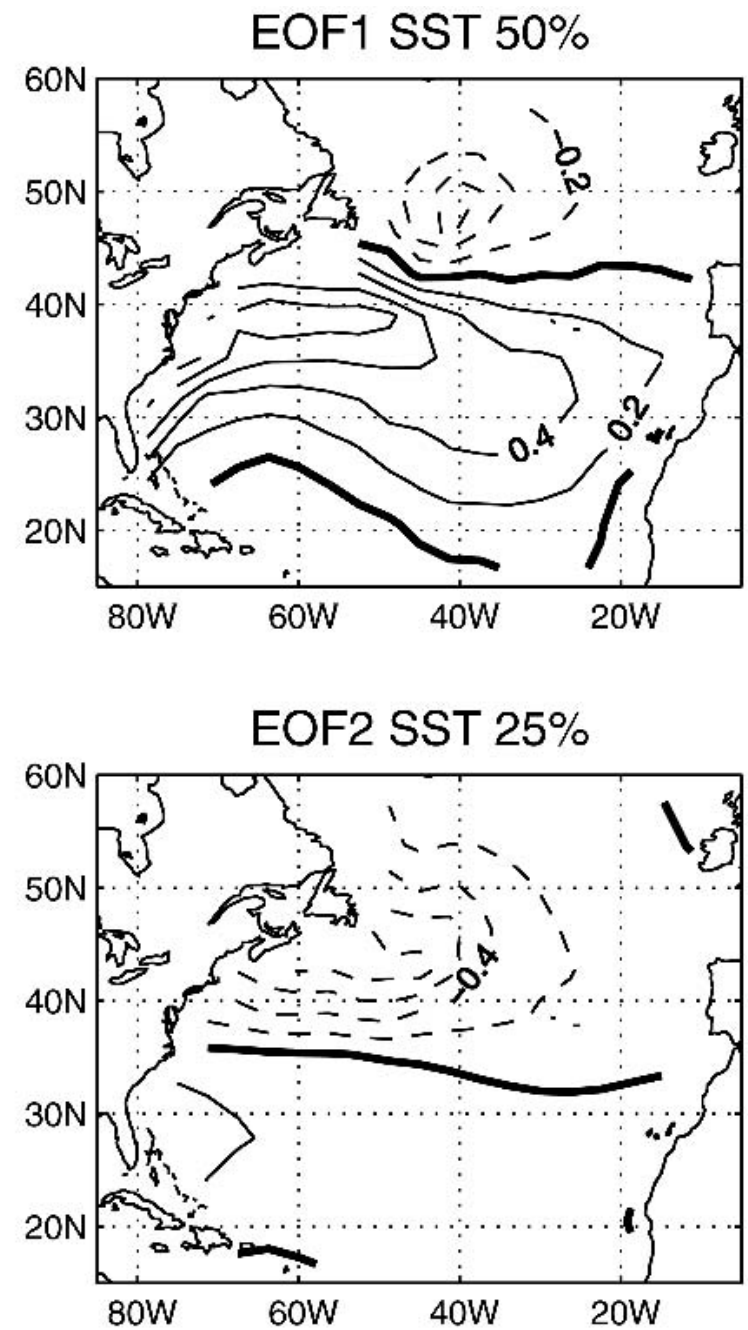

FIG. 2. First two EOFs of geopotential height at (left) $500 \mathrm{mb}(\mathrm{m})$ and (right) SST (K) in the coupled run. The percentage of variance explained is indicated. The PCs have been normalized so that each EOF indicates the typical mode magnitude. The negative and positive contours are dashed and solid lines, respectively. The zero contour is highlighted. The contour interval is $20 \mathrm{~m}$ for the atmosphere and $0.2 \mathrm{~K}$ for the SST.

centered south of Newfoundland. The two modes show some similarity with the first two observed modes in the North Atlantic except south of about $25^{\circ} \mathrm{N}$ (the first observed mode is a tripole), presumably because of the QG approximation in the atmosphere.

The persistence of the NAO and EAP, estimated from their principal component (PC) autocorrelation function (Fig. 3, left), are 2.8 and 0.5 months, respectively. The persistence of the EAP is realistic because the NAO is longer than the observed value of about a month (Hurrel and van Loon 1997). This bias primarily comes from the atmospheric model, although the coupling increases it (see below). Use of daily means shows that the autocorrelation of the NAO is realistic on a short time scale (lags $\leq 10$ days) and that the bias only appears for a longer time scale, possibly because of the absence of a seasonal cycle. Probably for the same reason, the SST persistence is larger than observed, in particular for PC1 ( 8 and 5 months for PC1 and PC2, respectively, compared to about 4 months).

For the purpose of this study, we are interested in the observed relationship between the SST and Z500 modes being well reproduced in the model: the NAO forces SST EOF1 while the EAP forces SST EOF2. As in observations and consistent with the stochastic climate model (Frankignoul and Hasselmann 1977), the cross correlation between the atmospheric and SST PCs reaches a maximum when the SST lags by 1 month and then slowly decreases on the SST time scale (Fig. 3). When the SST leads, the cross correlation is smaller, 

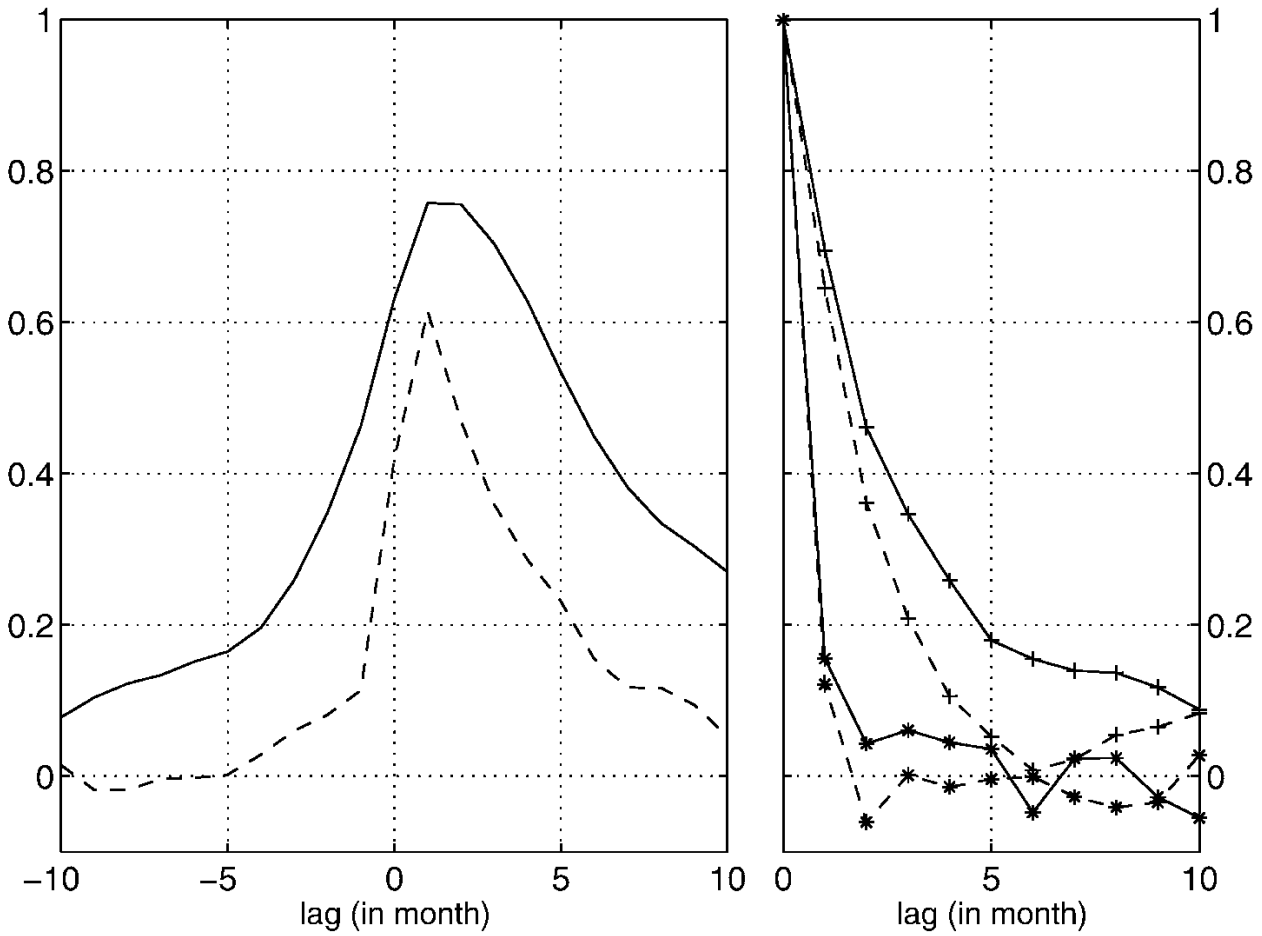

FIG. 3. (left) Lagged cross correlation between the PC1s (solid) and PC2s (dashed) of Z500 and SST in the coupled run. The atmosphere leads at positive lags. (right) Autocorrelation function of PC1 (plus) and PC2 (stars) of Z500 in the coupled (solid) and uncoupled (dashed) runs.

mostly reflecting the persistence of the associated atmospheric mode. The cross correlations underscore that air-sea interactions are dominated by the atmosphere forcing the SST. The heat flux is the dominant forcing, although advection by Ekman currents significantly reinforces it north of $45^{\circ} \mathrm{N}$. As in Czaja and Frankignoul (1999), once the SST anomaly is created, the surface heat flux tends to damp it; that is, there is a negative heat flux feedback (not shown).

Anticipating the quantification of the feedbacks in sections $3 \mathrm{c}$ and $3 \mathrm{~d}$, we estimated the atmospheric patterns that force the SST EOFs in the coupled run more precisely by regressing the monthly mean geopotential height anomalies at each level onto the SST PCs 1 month later. The results at $500 \mathrm{mb}$ are displayed in Fig. 4. The forcing pattern of SST EOF1 closely resembles a positive NAO phase. However, the forcing pattern of SST EOF2 slightly differs from the EAP with a more symmetric dipole over the North Atlantic and larger hemispheric extensions. The second EOF of atmospheric variability is thus not exactly the pattern of dynamical relevance in the air-sea interactions, at least in our model (see also section 4). This may explain the lower correlations for PC2s in Fig. 3 (left).

\section{c. Coupled versus uncoupled atmospheric variability}

To gain insight into the influence of the SST fluctuations on the atmosphere, we made a parallel 1000- month (after spinup) simulation in which the SST was prescribed from the coupled run climatology, and thus the SST variability had been removed. At $500 \mathrm{mb}$, the mean coupled minus uncoupled geopotential height difference resembles a weak, but statistically significant, positive NAO phase (maximum amplitude of $15 \mathrm{~m}$, not shown), consistent with the nonlinear SST anomaly influence discussed below. Throughout the atmospheric column, the variability is enhanced by the coupling, more strongly so in the Atlantic and west Pacific areas (the monthly geopotential height variance in the North Atlantic increases by $11 \%, 10 \%$, and $6 \%$ at 200,500 , and $800 \mathrm{mb}$, respectively), while it is decreased by $9 \%$ for the heat flux. The transient eddy variability shows no significant changes. The spatial structure of the main EOFs is virtually indistinguishable from their coupled counterparts, but their temporal behavior is modified, in particular for the NAO whose variance is $14 \%$ larger in the coupled mode versus $10 \%$ for EAP. The different impact of the coupling is even more striking for the persistence (Fig. 3, right): the NAO persistence increases from 2.0 to 2.8 months while the EAP one is hardly changed.

These features have been observed in other modeling studies (e.g., Manabe and Stouffer 1996; Saravanan and McWilliams 1998) and were explained by Barsugli and Battisti (1998), using a simple one-dimensional energybalanced atmosphere. At low frequency, the SST adjusts to the air temperature variability resulting from 

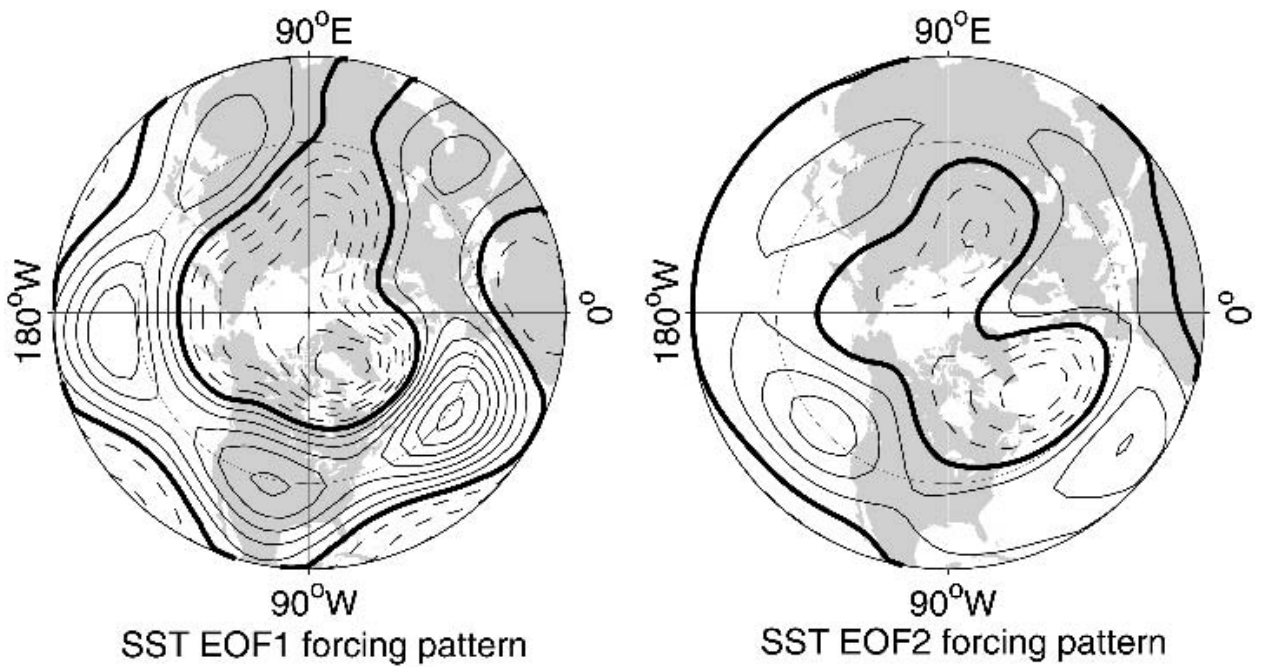

FIG. 4. Regression of the geopotential height anomalies at $500 \mathrm{mb}$ onto (left) the SST PC1 and (right) the SST PC2 1 month later. The negative and positive contours are dashed and solid lines, respectively. The zero contour is highlighted and the contour interval is $10 \mathrm{~m}$.

the natural atmospheric variability, thereby reducing the negative heat flux feedback and enhancing the atmospheric variability. Taking into account linearized atmospheric dynamics, Ferreira et al. (2001) showed that the low-frequency enhancement should be the strongest at the largest spatial scale, as found here for the NAO. However, it is shown below that the transient eddy dynamics also plays a key role in the mode enhancement by coupling.

\section{The transient atmospheric response to SST EOF1}

To understand how coupling selectively enhances the atmospheric variability, we have investigated the transient atmospheric response to prescribed SST anomalies taken from the coupled run. Here, we focus on the atmospheric response to the main SST anomaly pattern (EOF1) while the response to SST EOF2 is described in section 4. In the main experiment, the EOF1 SST anomaly in the phase shown in Fig. 2 (i.e., as forced by a positive NAO phase), but with an amplitude multiplied by 3 [hereafter EOF1 $\times(+3)$ ] is added to the SST climatology of the previous runs. To have a sufficient signal-to-noise ratio, a 400 -member ensemble of 10 month experiments is performed using independent initial conditions taken in the uncoupled run. Twice-daily values are saved over the first two months and monthly means thereafter.

\section{a. The transient response}

The ensemble mean geopotential height response to EOF1 $\times(+3)$ is shown for the first month in Fig. 5 at 500 (left) and $800 \mathrm{mb}$ (right). The response at $200 \mathrm{mb}$ is similar to that at $500 \mathrm{mb}$ except for a twice-larger am- plitude (not shown). During the first week, the response is primarily characterized by a baroclinic perturbation over the North Atlantic with largest amplitude above the positive (southern) pole of the SST anomaly, a trough at $800 \mathrm{mb}$ and a ridge at 500 (and 200) $\mathrm{mb}$. The response is small and only significant at the $5 \%$ level (a two-sided Student's $t$ test) at $800 \mathrm{mb}$. By the second week, the Z500 ridge has grown stronger and started to extend longitudinally, and a trough has appeared at both levels north of about $45^{\circ} \mathrm{N}$. The vertical structure is thus baroclinic over the southern SST pole and equivalent barotropic farther north. A fast barotropization at high latitudes was also found by $\mathrm{Li}$ and Conil (2003). In week 3, the Z500 dipole has grown further and the zonal spread over America and Eurasia becomes more significant. At $800 \mathrm{mb}$, the through over the southern SST pole has weakened, and that to the north has strengthened. The vertical structure nonetheless remains baroclinic over the southern SST pole, and is equivalent barotropic everywhere else. By week 4, the southern Z800 trough has almost disappeared while the other centers of action have kept growing and the North American ridge has started to expand eastward. At $500 \mathrm{mb}$, significant teleconnections are found throughout the $20^{\circ}-40^{\circ} \mathrm{N}$ latitude band.

By the first half of the second month (Fig. 6, top), the Z500 pattern with its teleconnections is fully established although the amplitudes keep increasing (note the change in contour interval). However, the Z800 pattern is still evolving as the initial trough has been replaced by a very weak, but growing ridge that forms a positive belt by the second half of month 2 . The response reaches its equilibrium equivalent barotropic spatial pattern by month 3 , and its equilibrium amplitude by month 4 . 


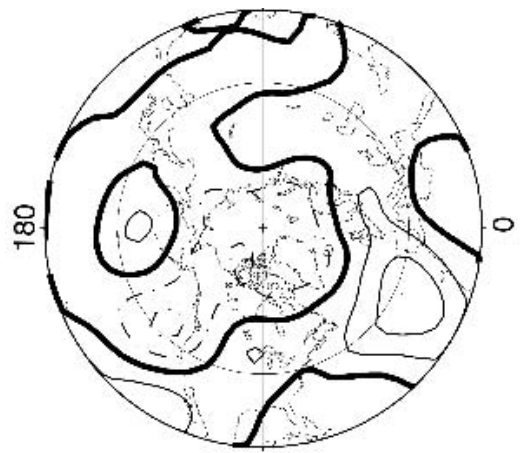

week 1

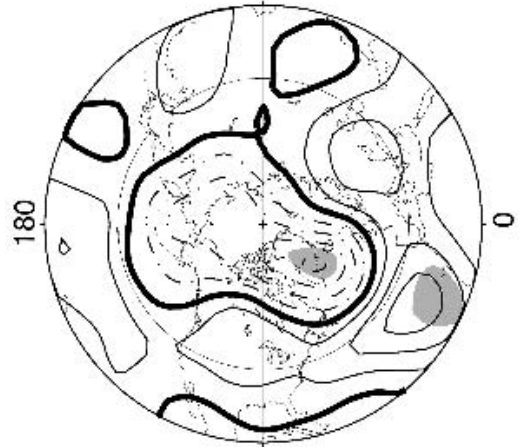

week 2
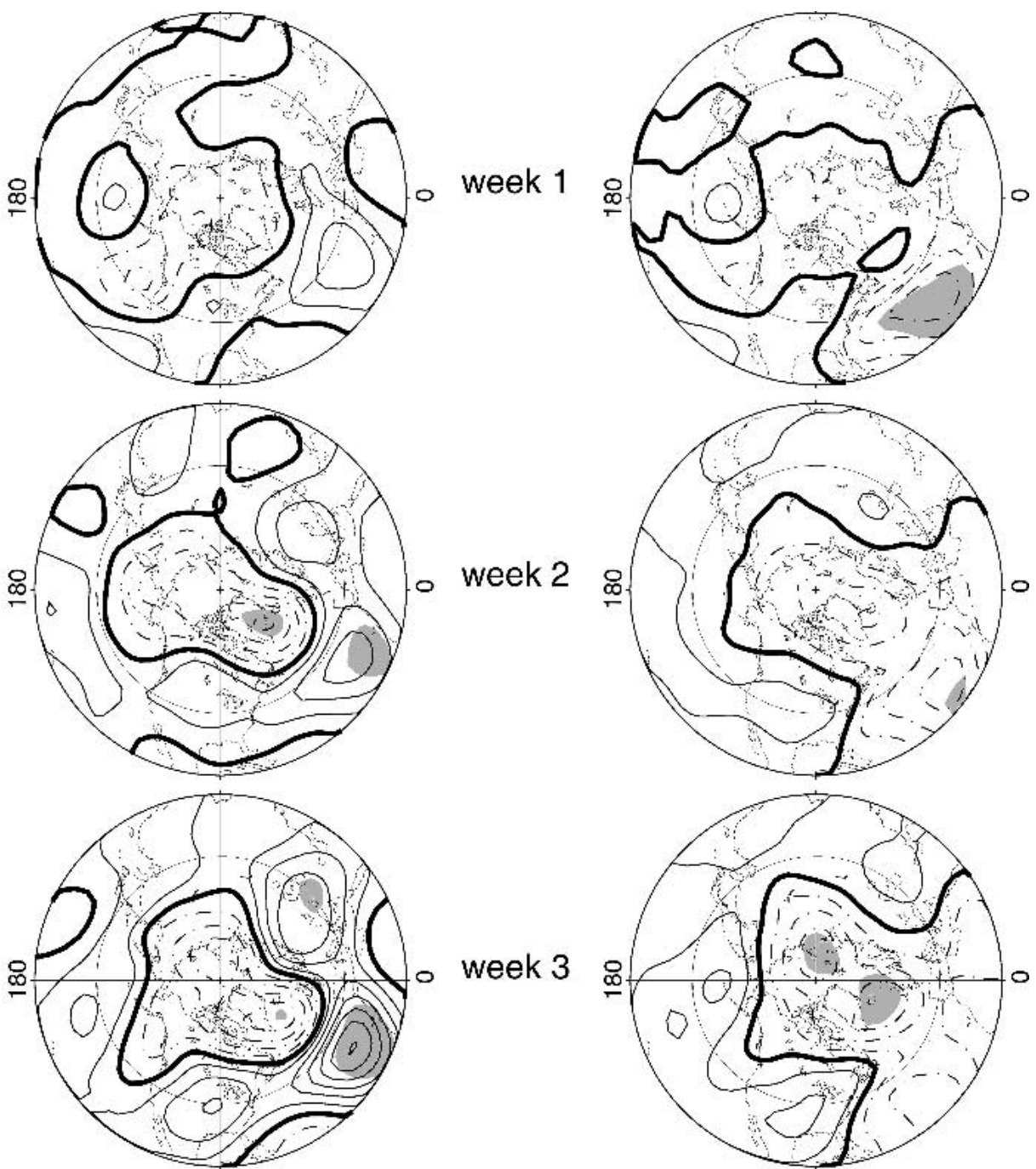

week 3
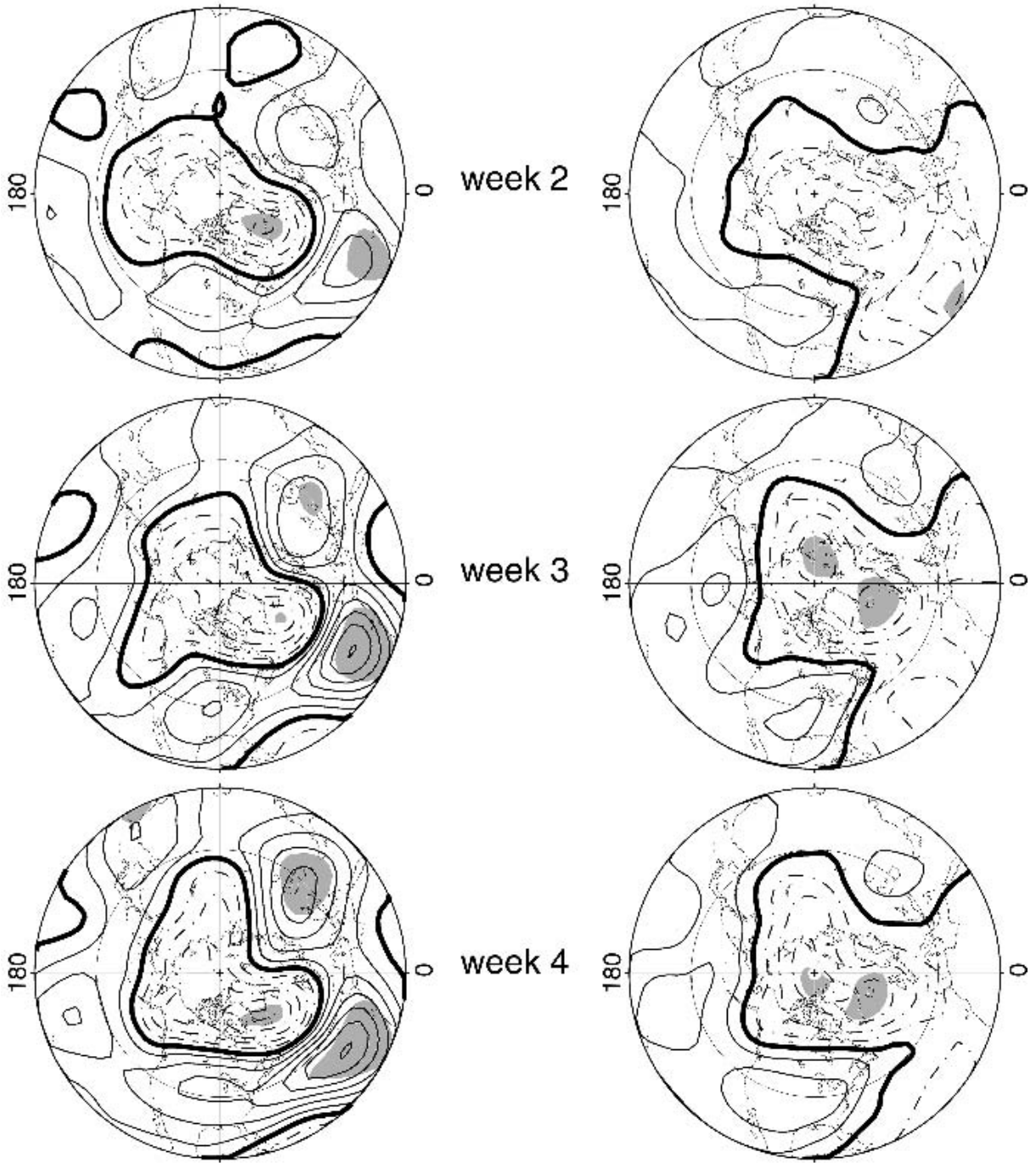

week 4
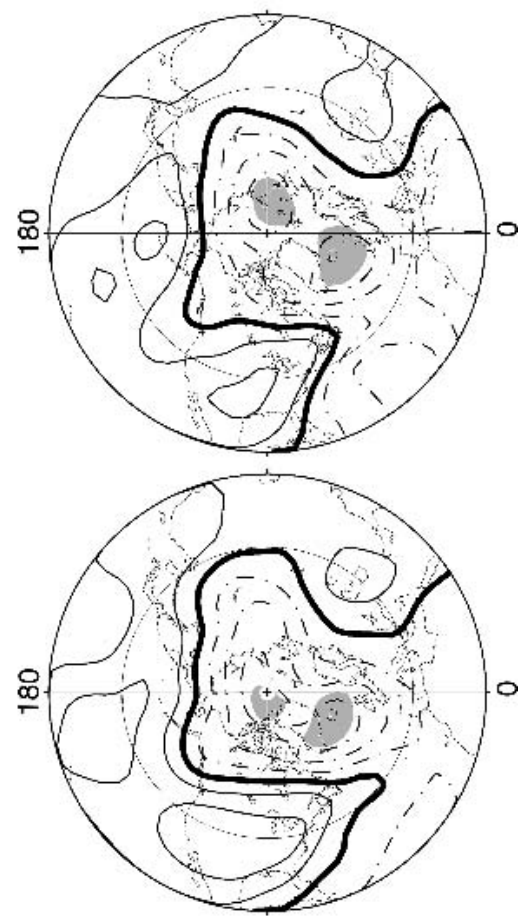

FIG. 5. Transient atmospheric response [geopotential height $(\mathrm{m})]$ to EOF1 $\times(+3)$ at $(\mathrm{left}) 500$ and (right) $800 \mathrm{mb}$. The response is shown as four successive weekly (7.5 days) averages over the first month. The positive and negative contours are solid and dashed lines, respectively. The zero contour is highlighted and the contour interval is $5 \mathrm{~m}$. The $5 \%$ and $1 \%$ levels of significance (two-sided Student's $t$ test) are indicated by light and dark gray shading.

Although the equilibrium response, defined as the mean over months $4-10$, is fully hemispheric, it is a maximum over the North American-Atlantic sector (Fig. 6, bottom). The vertical structure is equivalent barotropic, with a ridge (trough) above the warm (cold) SST anomaly. This type of stationary response has been observed in Palmer and Sun (1985) and other AGCMs (see Kushnir et al. 2002). Here, note that the response 

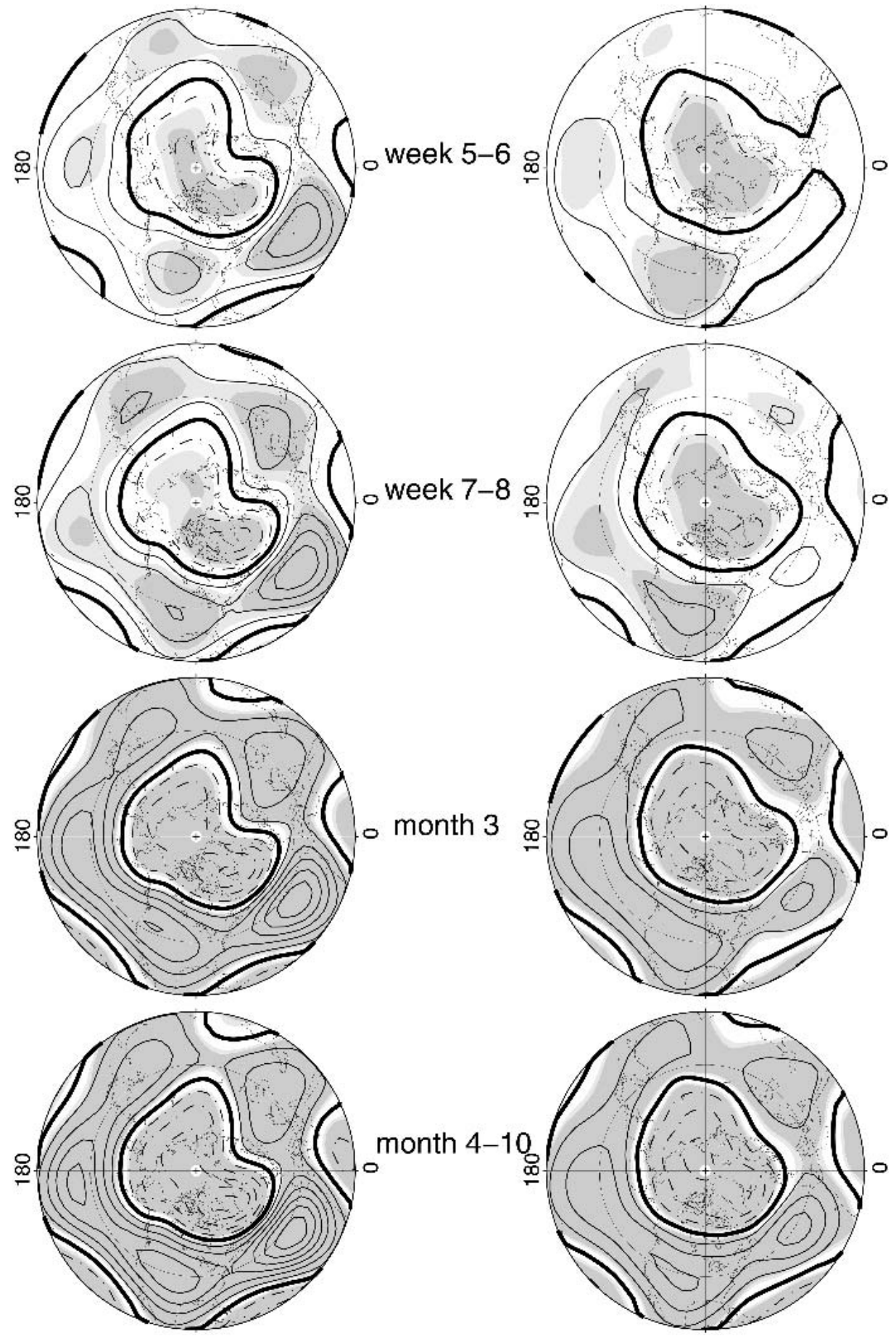

FIG. 6. Same as in Fig. 5 except for months $2-10$. The response is averaged over two 15 -day periods at month 2 , a monthly mean at month 3 , and months $4-10$ are averaged together defining the equilibrium response. The contour interval is $10 \mathrm{~m}$.

resembles the positive NAO phase, which forced the SST EOF1 in the coupled run, suggesting a positive feedback onto the atmosphere. Defining the atmospheric sensitivity as the ratio of the maximum Z500 response to the maximum SST anomaly yields a sensi- tivity of $20 \pm 2 \mathrm{~m} \mathrm{~K}^{-1}$ where the error bar is the $95 \%$ confidence interval on the ensemble mean assuming Gaussianity. In the observations, Czaja and Frankignoul (2002) estimated the sensitivity of the NAO to the North Atlantic SST to be about $25 \mathrm{~m} \mathrm{~K}^{-1}$. AGCMs 


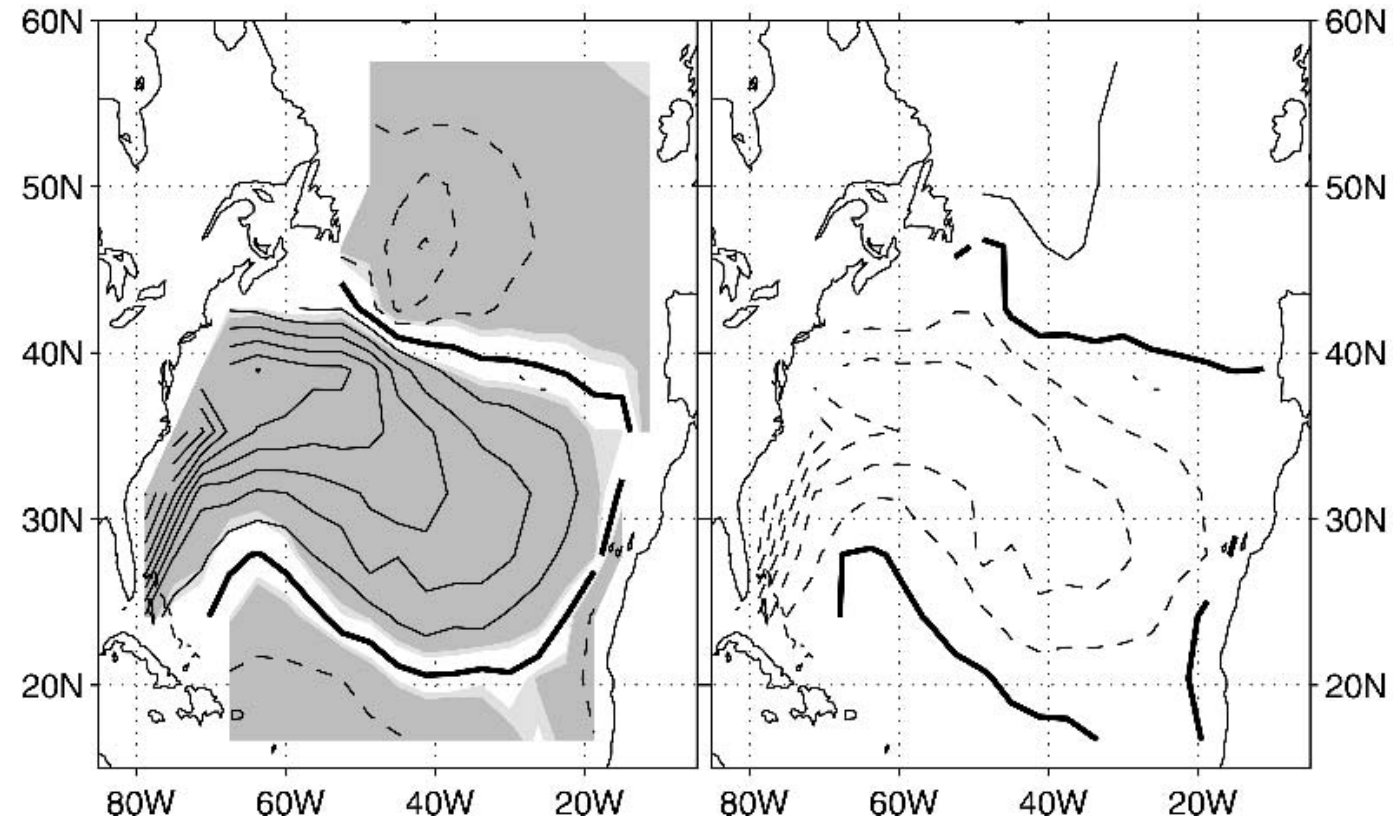

FIG. 7. (left) Initial (first week) surface heat flux anomaly and (right) difference between the equilibrium anomaly (months 4-10 average) and the initial anomaly in $\mathrm{W} \mathrm{m}^{-2}$. The negative and positive contours are dashed and solid lines, respectively. The zero contour is highlighted. The contour interval is (left) 20 and (right) $10 \mathrm{~W} \mathrm{~m}^{-2}$. A positive flux is directed into the atmosphere.

lead to a wide range of values from 15 up to $40 \mathrm{~m} \mathrm{~K}^{-1}$. Our result thus compares favorably with the observations and with modeling studies based on more sophisticated AGCMs, suggesting that our simple model behaves realistically.

\section{b. Main dynamics}

As shown above, the atmospheric response is basically baroclinic during the first month, but then equivalent barotropic up to equilibrium. Here, we briefly consider the basics mechanisms underlying this transient behavior, primarily focusing on the role played by the transient eddy fluxes and the air-sea heat exchanges.

If each variable is decomposed into a slowly varying part (denoted by an overbar) and an eddy part (denoted by a prime), the PV Eq. (1) transforms to

$$
\begin{aligned}
\frac{\partial \bar{q}}{\partial t}= & -J(\bar{\psi}, \bar{q})-\overline{J\left(\psi^{\prime}, \nabla^{2} \psi^{\prime}\right)}-\overline{\left(\psi^{\prime}, \frac{\partial}{\partial p}\left(\frac{f_{o}^{2}}{\sigma} \frac{\partial \psi^{\prime}}{\partial p}\right)\right)} \\
& -\frac{f_{o} R}{C_{\mathrm{pa}}} \frac{\partial}{\partial p}\left(\frac{\bar{Q}}{p \sigma}\right)-D(\bar{\psi})+S .
\end{aligned}
$$

The tendencies of the mean PV due to the dynamical nonlinearities appear on the rhs as the convergence of the eddy momentum flux (second term) and the eddy heat flux (third term), which together form the convergence of the eddy PV flux. Note that nonlinearities are also included in the tendency due to the diabatic heating because of the flow-dependent parameterization of the surface heat flux (5). The corresponding streamfunction tendencies are readily computed from

$$
\frac{\partial \psi}{\partial t}=\left[\nabla^{2} .+\frac{\partial}{\partial p}\left(\frac{f_{o}^{2}}{\sigma} \frac{\partial \cdot}{\partial p}\right)\right]^{-1} \frac{\partial q}{\partial t},
$$

which include both the eddy flux convergences and the associated eddy-induced circulations (Lau and Holopainen 1984).

The transient atmospheric response is initiated by the anomalous surface heat flux $F^{\prime}$. Its first-week average shows a striking similarity with the SST pattern, albeit with a much larger contrast between the two lobes (Fig. 7 , left). This largely results from the latitudinal dependence of the surface wind speed and of the Bowen ratio entering the surface heat flux (5). Above the positive southern SST lobe, the flux is upward while it is downward over the northern negative lobe, thus everywhere damping SST EOF1. In fact, $F^{\prime}$ is initially well approximated by the anomalous flux resulting from the climatological wind of the uncoupled run $\mathbf{U}_{s}^{u}$ blowing over the SST anomaly $T^{\prime}$ :

$$
F^{\prime} \simeq \rho_{a} C_{H} C_{\mathrm{pa}}\left(1+B^{-1}\right)\left|\mathbf{U}_{s}^{u}\right| T^{\prime} .
$$

The anomalous geopotential height tendency at 500 and $800 \mathrm{mb}$ due to the first-week averaged surface heat flux is shown in Fig. 8. The patterns are almost exactly opposite to each other (their sum is compensated by a small contribution at $200 \mathrm{mb}$ ), with a positive tendency at $500 \mathrm{mb}$ and a negative one at $800 \mathrm{mb}$ above the positive SST pole. The opposite holds above the nega- 


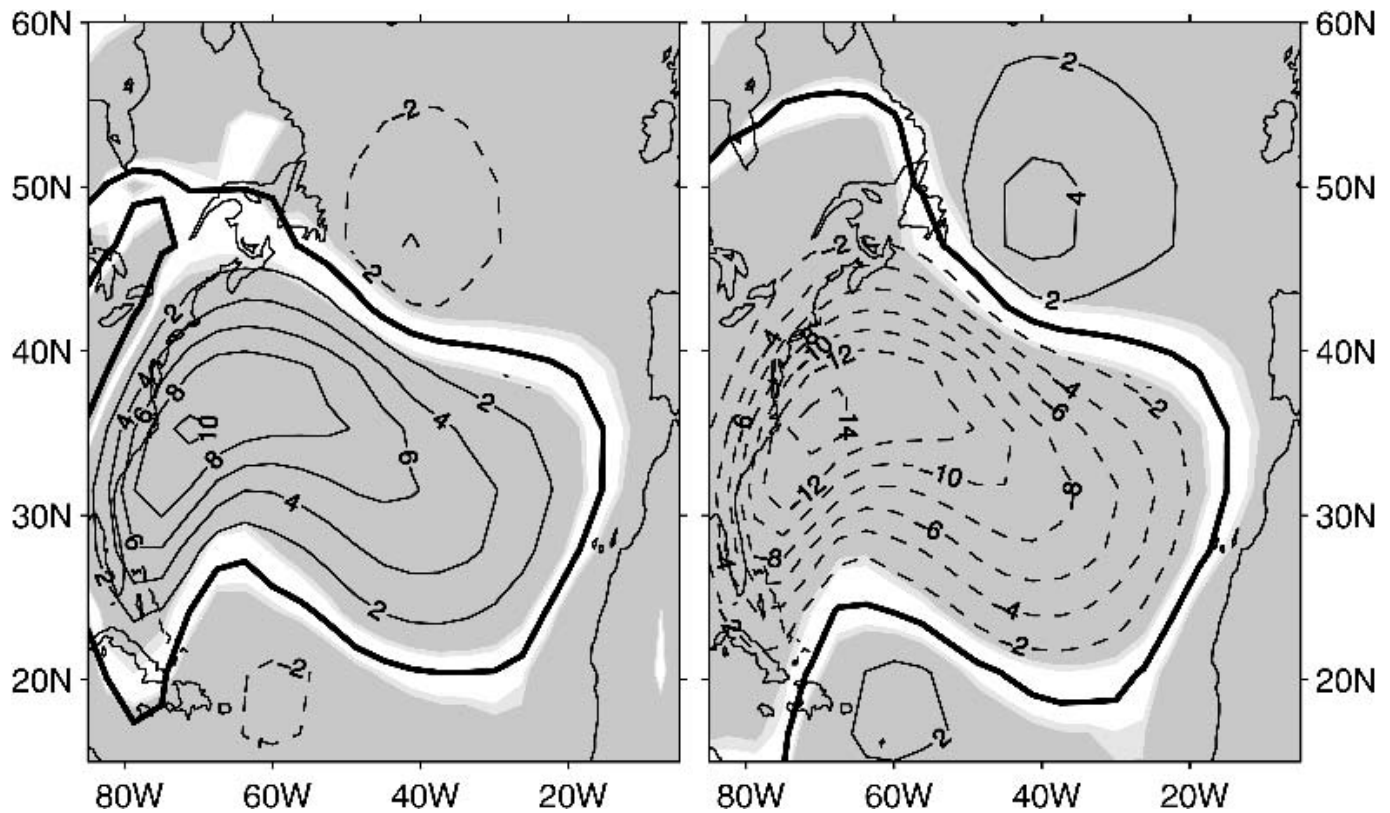

FIG. 8. Geopotential height tendency ( $\mathrm{m} \mathrm{s}^{-1}$ ) at (left) 500 and (right) $800 \mathrm{mb}$ due to the anomalous surface heat flux averaged over the first week. The negative and positive contours are dashed and solid lines, respectively. The zero contour is highlighted and the contour interval is $2 \times 10^{-5} \mathrm{~m} \mathrm{~s}^{-1}$. The $5 \%$ and $1 \%$ levels of significance are indicated by light and dark gray shading.

tive pole, but the amplitudes are much weaker. The baroclinic structure of the tendency results from the expansion or the contraction of the atmospheric column in response to the surface heat flux. It is reflected in the geopotential height response over the first week (Fig. 5, top). The initial structure is similar to the baroclinic response to extratropical heating predicted by linear theory and robustly found in linear time-independent AGCMs for a wide choice of climatology or heating anomaly (e.g., Hall et al. 2001a). As shown by Hoskins and Karoly (1981), the linear response is found downstream of the diabatic heating so that the latter is balanced by the anomalous meridional advection of heat. Here, the baroclinic response is not equilibrated and this may explain the absence of a downstream shift at $800 \mathrm{mb}$. However, in the first week, there is a hint of it at $500 \mathrm{mb}$. Li and Conil (2003), using a more comprehensive AGCM, similarly observed an initial baroclinic response to prescribed SST anomaly with an inphase response in the lower atmosphere and a slight downstream shift above.

Using a storm track model, Peng and Whitaker (1999) showed that such a baroclinic response could generate anomalous transient eddy momentum fluxes whose feedback could lead to an equivalent barotropic response. To test if such mechanism is at work in our model, the transient eddy fluctuations were computed during the first two months when twice-daily outputs were saved. Because of Blackmon's (1976) filtering procedure, the eddy fluctuations are only available from weeks 2 to 7 . During this period, a storm track anomaly with a large-scale dipole pattern and an equivalent barotropic structure developed to reach a maximum amplitude of $10 \mathrm{~m}$ at $500 \mathrm{mb}$ (not shown). It corresponds to a northward shift of the climatological storm track with an increased eddy activity at $50^{\circ} \mathrm{N}$ and a decrease at $30^{\circ} \mathrm{N}$, consistent with Lau and Nath (1991). The geopotential height tendencies due to the convergence of the anomalous heat and momentum eddy fluxes, averaged over weeks 2 and 7, are shown over the North Atlantic at 500 and $800 \mathrm{mb}$ in Figs. 9 and 10 (the tendencies at $200 \mathrm{mb}$ behave similarly to those at $500 \mathrm{mb}$ ). The most striking feature is their (statistically significant) large-scale pattern. The eddy heat tendency has a baroclinic profile. At $500 \mathrm{mb}$, it is composed of zonally elongated bands: negative ones north of $45^{\circ} \mathrm{N}$ and south of $30^{\circ} \mathrm{N}$, and a positive one in between. The pattern at $800 \mathrm{mb}$ is very similar but with the reversed sign (the three levels add to zero). The eddy momentum tendency has an equivalent barotropic structure, but it is less significant and somewhat noisier. In both cases, the structures hardly change with time, but the amplitudes increase slightly. The heat and momentum components oppose each other at 500 and 200 $\mathrm{mb}$ but reinforce each other at $800 \mathrm{mb}$. The total eddy forcing is almost null at $500 \mathrm{mb}$ where the two eddy components have similar amplitude, but reinforce the geopotential anomaly at $200 \mathrm{mb}$ where the momentum component is twice the heat one. At $800 \mathrm{mb}$, a strong dipole is obtained with a negative center at $55^{\circ} \mathrm{N}$ and a positive one at $35^{\circ} \mathrm{N}$. A comparison with the corresponding geopotential anomalies in Fig. 5 shows that, 

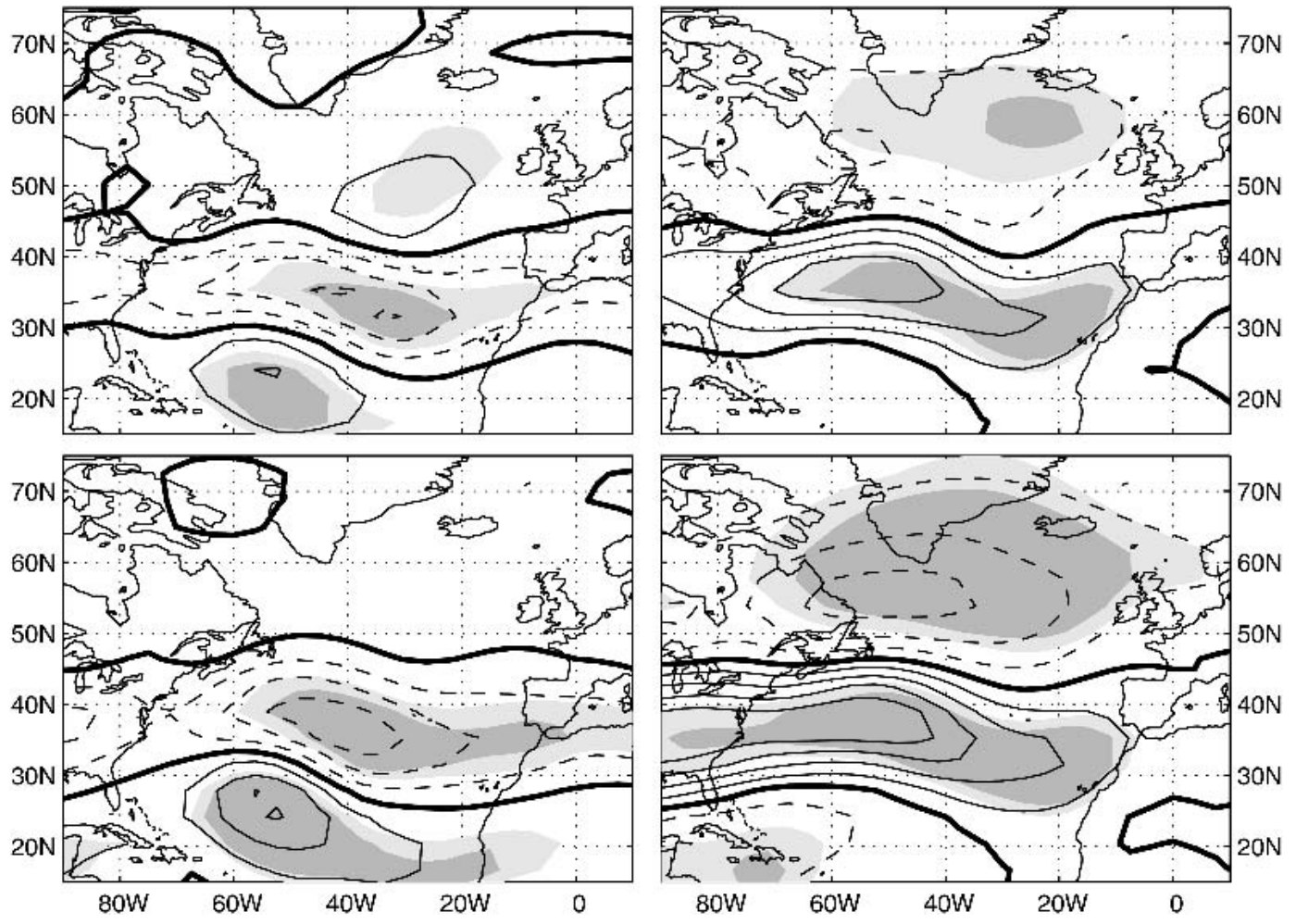

FIG. 9. Geopotential height tendency at (left) 500 and (right) $800 \mathrm{mb}$ due to the convergence of anomalous transient eddy heat fluxes averaged over weeks (top) 2 and (bottom) 7. The contour interval is $0.3 \times 10^{-5} \mathrm{~m} \mathrm{~s}^{-1}$.

during the first week, the net eddy tendency damps both the $\mathrm{Z} 800$ trough centered at $35^{\circ} \mathrm{N}$ and the very weak ridge south of Greenland, thus initially exerting a negative feedback. Afterward, the eddy forcing enhances the negative anomaly that has appeared above Greenland while continuing to damp the Z800 trough until it disappears around week 4 or 5. From then on, the eddy forcing is everywhere positively correlated with the Z800 anomaly (positive feedback).

This behavior is consistent with the scenario put forward by Peng and Whitaker (1999) and Peng et al. (2003). However, they do not consider the role of the eddy heat flux that, in our case, is as important as the eddy momentum fluxes, at least during the first two months of the transient evolution.

\section{c. Estimation of the feedback}

Since the SST anomaly that results from a positive NAO phase, has a positive NAO-like impact on the atmosphere, there is a positive feedback. Here, we quantify this feedback and determine how it alters the (negative) heat flux feedback onto the SST. Note that the SST anomaly was held fixed in the sensitivity experiments although, ideally, the retroaction should be studied in the coupled mode.

To quantify the feedback, we use the atmospheric pattern that forces SST EOF1 in the coupled run
(Fig. 4, left), but multiplied by the factor of 3 used in the sensitivity experiment. At each level, the transient atmospheric response to EOF1 $\times(+3)$ is then spatially correlated with and projected upon the forcing pattern, thereby quantifying the similarities in shape and amplitude between forcing and response as a function of time. Figure 11 shows the results for the North Atlantic domain $\left(15^{\circ}-75^{\circ} \mathrm{N}, 90^{\circ} \mathrm{W}-10^{\circ} \mathrm{E}\right)$, but similar results are found for the Northern Hemisphere.

Right from the beginning, the Z500 response resembles a positive NAO phase (correlation $\geq 0.8$ ). As expected, the Z800 response is first negatively correlated with the positive NAO, but it rapidly evolves so that the two levels have nearly identical correlations with the forcing pattern after 1 month. The spatial correlation at both levels keep increasing slowly until month 4, stabilizing around 0.96 . Results at $200 \mathrm{mb}$ closely resemble those at $500 \mathrm{mb}$, so that the equilibrium response pattern is very similar to a positive NAO at all levels. The projections at 500 and $800 \mathrm{mb}$ evolve from near zero to an equilibrium value by month 4 of 28 $\pm 3 \%$ and $24 \pm 3 \%$ of the forcing amplitude at 500 and $800 \mathrm{mb}$, respectively. The positive feedback at equilibrium is thus substantial. Note that it is an upper bound for the positive feedback at play in the coupled system where the SST varies and the equilibrium atmospheric response is probably not reached.

It was found (Fig. 7, left) that the surface heat flux 

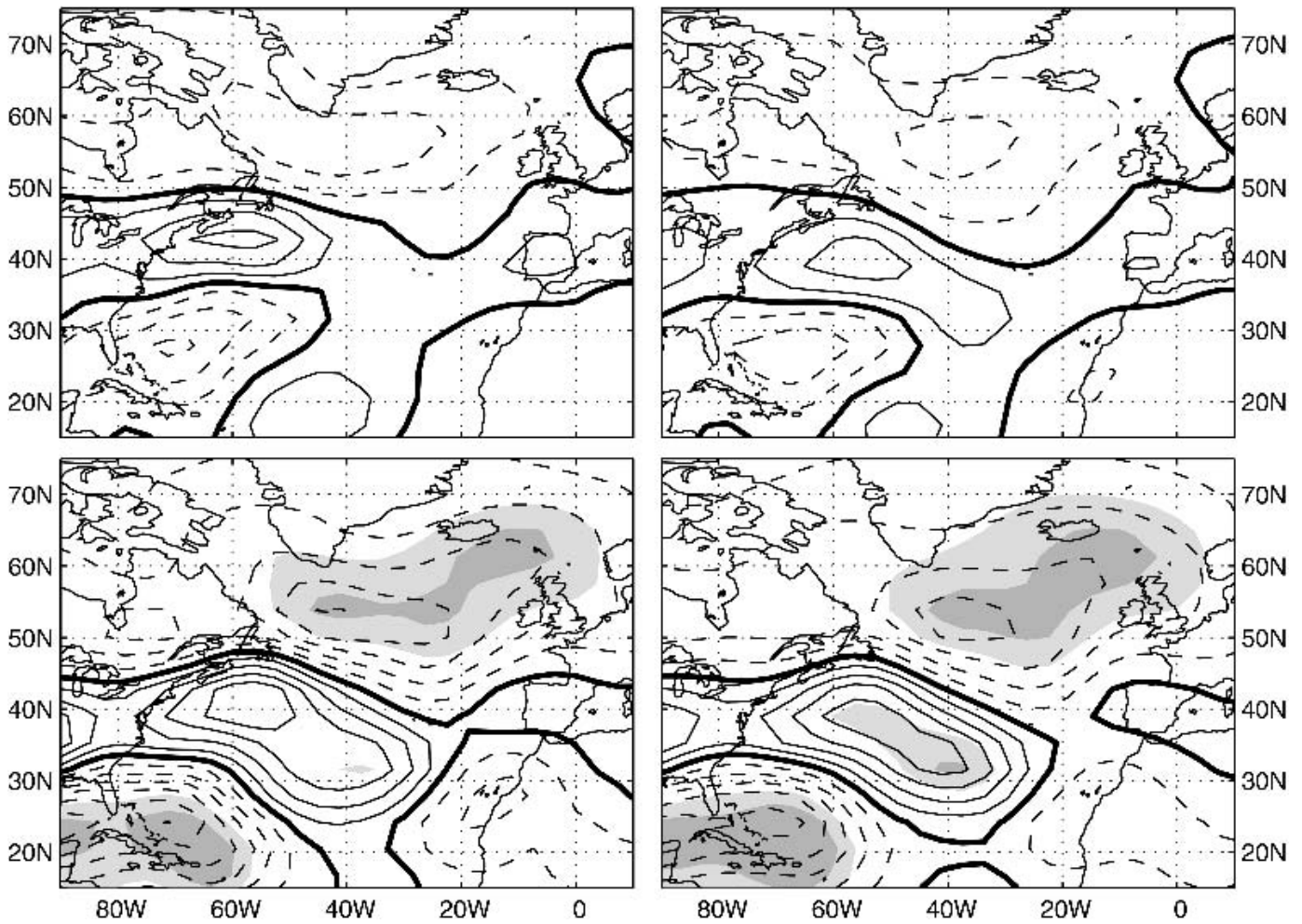

FIG. 10. Same as in Fig. 9 except for the transient eddy momentum flux.

anomaly tends to initially damp SST EOF1. This tendency persists throughout the 10 months of the sensitivity experiment since the pattern of the anomalous heat flux remains approximately the same. However, its amplitude slightly decreases as the atmospheric response builds up. The difference $\Delta F^{\prime}$ between the equilibrium (months 4-10) and the initial (first week) heat flux anomaly (Fig. 7, right) is due to the atmospheric response to EOF1 $\times(+3)$. Since the latter corresponds to a positive NAO phase, $\Delta F^{\prime}$ tends to force an SST EOF1-like anomaly, thus opposing the initial damping effect. However, the atmospheric response is never large enough to overcome the initial damping and the heat flux feedback remains negative, albeit weaker. The time evolution of the heat flux feedback in the North Atlantic sector (positive for a negative feedback) is obtained by projection of the heat flux anomaly onto the EOF1 $\times(+3)$ pattern (Fig. 11, bottom). The negative feedback, initially about $39 \mathrm{~W} \mathrm{~m}^{-2} \mathrm{~K}^{-1}$, weakens almost linearly until month 4 and then fluctuates around $27 \mathrm{~W} \mathrm{~m}^{-2} \mathrm{~K}^{-1}$, a $32 \%$ reduction.

\section{d. Sensitivity experiments}

To test how the results depend on the phase and the amplitude of the SST anomaly, a set of experiments was conducted with an SST anomaly equal to -3 times, then \pm 2 times SST EOF1, and then only with the northern or southern pole of the SST anomaly. As the results are qualitatively very similar to the previous ones, they are only briefly discussed.

The initial response to EOF1 $\times(-3)$ is baroclinic as in Fig. 5, but with a reversed sign. However, the response evolves more rapidly. The vertical structure becomes equivalent barotropic as soon as the third week, and the response reaches equilibrium by the end of month 2 . The equilibrium pattern [mean over months 4-10 as for $\mathrm{EOF} \times(+3)]$ is shown in Fig. 12 at $500 \mathrm{mb}$. It resembles a negative phase of the NAO, which forces the negative phase of the SST EOF1, hence the feedback onto the atmosphere is still positive. However, the spatial correlation of the response with the negative NAO is only 0.86 at equilibrium, which is slightly smaller than in case of EOF1 $\times(+3)$. The amplitude is also smaller, given the atmospheric sensitivity of $14 \pm 2 \mathrm{~m} \mathrm{~K}^{-1}$ at 500 $\mathrm{mb}$, which is about 1.5 smaller than for EOF1 $\times(+3)$. The weaker amplitude and the smaller spatial correlation together leads to a smaller positive feedback: the atmospheric response is $15 \%$ and $9 \%$ of the forcing at 500 and $800 \mathrm{mb}$, respectively. The weaker response is also reflected in the negative heat flux feedback that only decreases by about $10 \%$ from the initial value of about $39 \mathrm{~W} \mathrm{~m}^{-2} \mathrm{~K}^{-1}$ (Fig. 11, dashed). Since the initial heat flux feedback is the same for the two polarities, the asymmetry results from subsequent atmospheric nonlinearities. The transient eddy heat forcing for EOF1 $\times$ $(-3)$ is almost exactly opposite to that obtained for EOF1 $\times(+3)$ (not shown). On the contrary, the mo- 

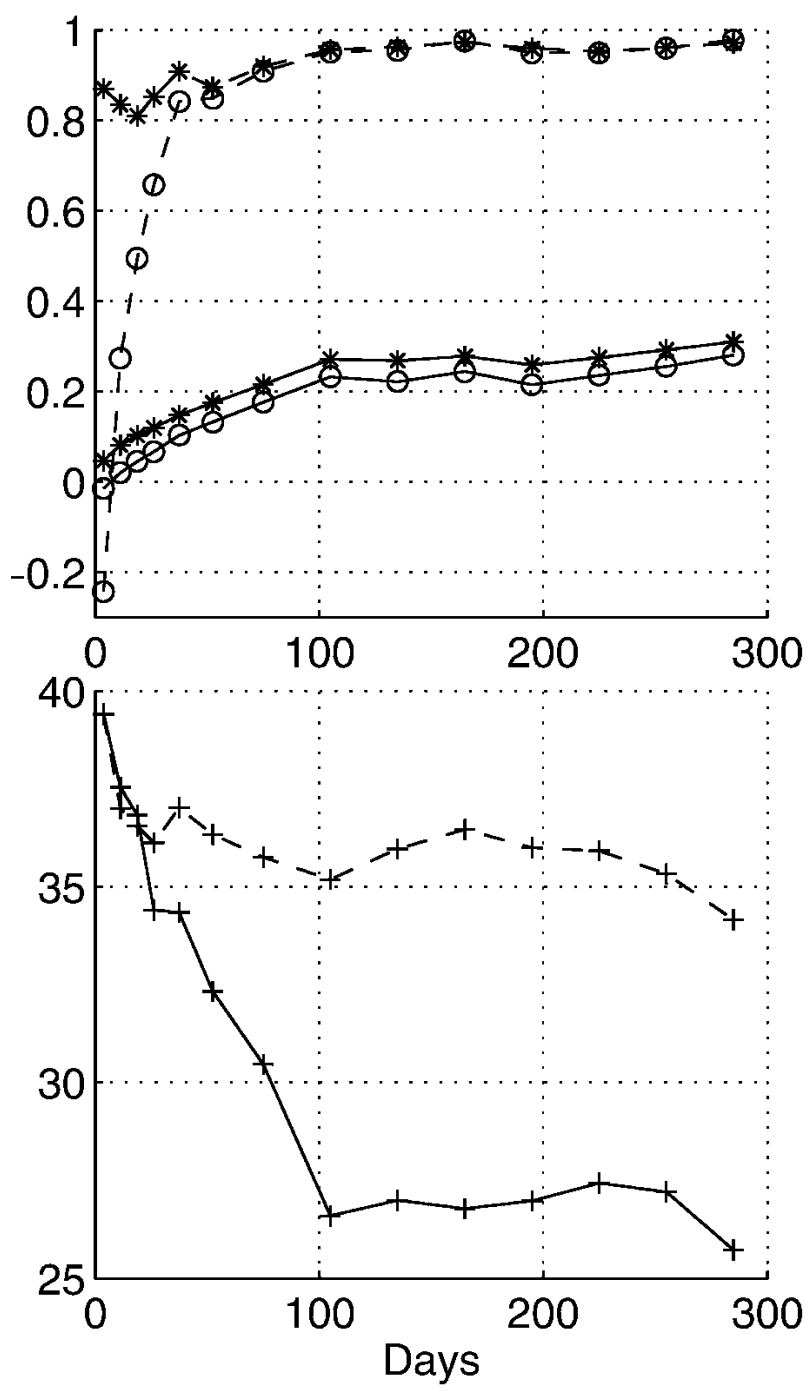

FIG. 11. (top) Spatial correlation (dashed) between the response and the forcing patterns of EOF1 $\times(+3)$ and projection (solid) of the response onto that pattern vs time at 500 (stars) and $800 \mathrm{mb}$ (circles). (bottom) Heat flux feedback $\left(\mathrm{W} \mathrm{m}^{-2} \mathrm{~K}^{-1}\right)$ as a function of time for the EOF1 $\times(+3)$ (solid) and EOF1 $\times(-3)$ (dashed) cases, estimated by projecting the anomalous surface heat flux onto the SST anomaly. It is positive when the former tends to damp the latter. In both panels, the time average intervals are those used in Figs. 5 and 6, except months 4-10 are kept separated.

mentum component is only reversed on the western part of the Atlantic basin $\left(\leq 30^{\circ} \mathrm{W}\right)$ and of the same sign as for EOF1 $\times(+3)$ farther east (quadrupole pattern). A weaker positive eddy momentum feedback may thus be responsible for the asymmetry. However, the asymmetry could be initiated by a nonlinear self-interaction of the large-scale response and the asymmetric eddy momentum forcing may only be its consequence (Branstator 1992). Peng et al. (2003) demonstrated that such a mechanism could explain the asymmetry noticed by Peng et al. (2002) although, in their case, the NAO-like response is more sensitive to the negative phase of the (observed) North Atlantic SST tripole.

Two 200-member ensemble experiments conducted with EOF1 $\times( \pm 2)$ show that, to a good approximation, the atmospheric response depends linearly on the amplitude of the SST anomaly as the sensitivities at 500 $\mathrm{mb}$, given by $18 \pm 4$ and $17 \pm 3 \mathrm{~m} \mathrm{~K}^{-1}$ for EOF1 $\times$ $(+2)$ and EOF1 $\times(-2)$, respectively, are not significantly different from their counterpart at amplitude 3 . The asymmetry between the positive and negative phase of the SST anomaly is still seen, but it is no longer significant, in part because of the smaller number of experiments. It is also reflected in the negative heat flux feedback that is initially about $38 \mathrm{~W} \mathrm{~m}^{-2} \mathrm{~K}^{-1}$ for both phases but decreases to 28 and $35 \mathrm{~W} \mathrm{~m}^{-2} \mathrm{~K}^{-1}$ for EOF1 $\times(+2)$ and EOF1 $\times(-2)$, respectively. Thus, the atmosphere seems more sensitive to an increase of the meridional SST gradient in the storm track region $[\mathrm{EOF} 1 \times(+2 / 3)]$ than to its decrease $[\mathrm{EOF} 1 \times(-2 / 3)]$.

The strong imprint of the southern SST EOF1 pole in the early stages of the response (Fig. 5) suggests that it plays a dominant role. This was confirmed by sensitivity experiments where \pm 3 times the northern and the southern poles of SST EOF1 were prescribed in isolation. We found that the equilibrium response to the southern SST pole was only slightly, but not significantly, different from the response to the complete SST anomaly. On the other hand, the atmospheric response to the northern SST pole was very weak $(\leq 10 \mathrm{~m}$ at 500 $\mathrm{mb}$ ), and hardly significant. The dominance of the southern SST pole is not only due to its larger amplitude, but also to the stronger heat flux feedback (and thus larger diabatic heating of the atmosphere) that results from the southward decrease of the Bowen ratio and the location of the wind speed maximum that is found near $35^{\circ}-40^{\circ} \mathrm{N}$.

\section{The transient atmospheric response to SST EOF2}

The same set of experiments were conducted with the second mode of SST variability (Fig. 2). The transient response to SST EOF2 multiplied by 3 is illustrated in Fig. 13 using somewhat shorter averaging intervals than in section 3 because of the faster response. As before, the initial local response is baroclinic with a trough at $500 \mathrm{mb}$ and a ridge at $800 \mathrm{mb}$ above the cold SST anomaly; the atmospheric tendency to damp the latter is associated to a downward surface heat flux and a decrease of the 500-800-mb thickness. The baroclinic response is very weak and only lasts for the first 5 days or so. In the next 10 days, the positive Z800 anomaly almost disappears, and by the second half of the month, it is replaced by a negative anomaly spreading over the Atlantic domain. Meanwhile, the Z500 negative anomaly has strengthened and drifted northward to settle slightly downstream of SST EOF2. In month 2, 

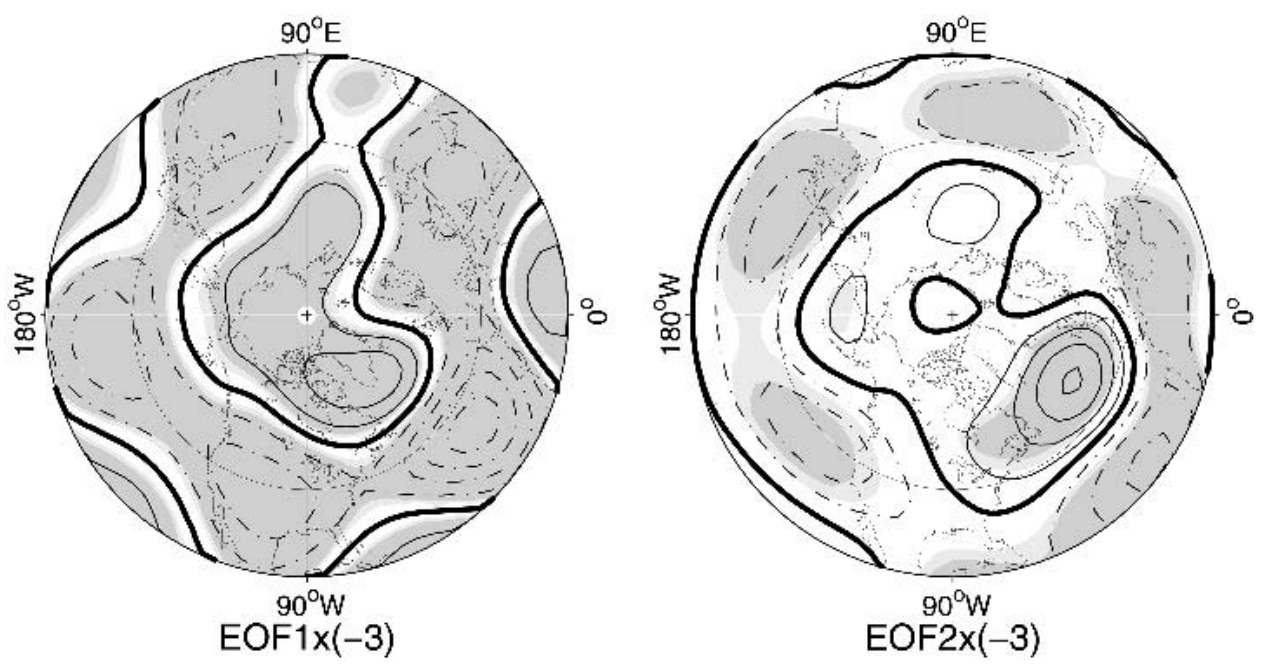

FIG. 12. Equilibrium atmospheric response to (left) EOF1 $\times(-3)$ (average of months 4-10) and (right) EOF2 $\times(-3)$ (average of months 3-10) at $500 \mathrm{mb}$. The contour interval is $10 \mathrm{~m}$ in the left panel and $5 \mathrm{~m}$ in the right one, otherwise same as in Fig. 5.

the response is equivalent barotropic over the whole Atlantic domain and equilibrium is reached in month 3. As in the case of EOF1, the response has developed significant hemispheric teleconnections, but remains maximum over the North Atlantic sector where a negative (positive) geopotential height anomaly overlies a cold (warm) SST anomaly. Over the Atlantic, the equilibrium response shows some similarity with the EAP pattern (Fig. 2), but more closely resembles the forcing pattern of SST EOF2 (Fig. 4), again suggesting a positive feedback. This further underscores that the second EOF of atmospheric variability is not exactly the pattern of dynamical relevance in the air-sea interactions. The atmospheric sensitivity at $500 \mathrm{mb}$ is $11 \pm 1 \mathrm{~m} \mathrm{~K}^{-1}$.

We also determined the response to EOF $2 \times(-3)$ and $\mathrm{EOF} \times( \pm 2)$. As in the previous case, the response is initially baroclinic, though weak and hardly significant, then evolves toward an equivalent barotropic that resembles the EAP in the North Atlantic sector. Its sign changes with the phase of the SST anomaly, suggesting a positive feedback in all cases. The Z500 equilibrium response to EOF2 $\times(-3)$ is shown in Fig. 12 (right) for comparison with Fig. 13. The sensitivity at $500 \mathrm{mb}$ are 8 $\pm 1,12 \pm 3$, and $10 \pm 3 \mathrm{~m} \mathrm{~K}^{-1}$ for EOF2 $\times(-3), \mathrm{EOF} 2$ $\times(+2)$, and EOF2 $\times(-2)$, respectively, showing a hint of an asymmetry between the positive and the negative phase of SST EOF2. As for SST EOF1, the atmosphere is most sensitive when the SST anomaly polarity corresponds to an increase of the meridional SST gradient. For a given polarity, the amplitude of the equilibrium response varies linearly with the amplitude of the SST anomaly.

The feedback resulting from the atmospheric response was quantified as previously but using the atmospheric pattern (Fig. 4) that forces SST EOF2 in the coupled run. The spatial correlation between the equi- librium response to SST EOF2 and the forcing pattern over the Atlantic domain is generally high, around 0.8 , except for the case of EOF2 $\times(-2)(0.36)$, confirming the visual impression of a positive feedback on the atmosphere. The projections show that the amplitude of the response at equilibrium is about $20 \%$ that of the forcing pattern for the positive SST EOF2 phase and about $10 \%$ for the negative one. As in the case of SST EOF1, the positive feedback on the atmosphere reduces the negative heat flux feedback on the SST anomaly. Its time evolution (not shown) is similar to that in Fig. 11, except for a faster adjustment. The initial negative heat flux feedback is about $35 \mathrm{~W} \mathrm{~m}^{-2} \mathrm{~K}^{-1}$ and it decreases by about $30 \%$ in the positive SST polarity and $10 \%$ in the negative one. Although the decrease is only significant for the positive SST EOF2 phase, it is similar to that found for SST EOF1.

\section{Summary and discussion}

Using an intermediate resolution atmospheric model, we have investigated the transient atmospheric response to prescribed extratropical SST anomalies. The SST anomalies were determined from a run of the model coupled over the North Atlantic to a slab oceanic mixed layer, so that they resulted from the twoway interaction in the coupled system and thus were consistent with the natural variability of the model atmosphere. The coupled model provides a fairly realistic simulation of the Northern Hemisphere extratropical air-sea interactions on the seasonal time scale with a satisfactory mean state, a good transient eddy activity, and a realistic interaction between the latter and the low-frequency variability. The model reproduced the main modes of extratropical atmospheric and SST low- 

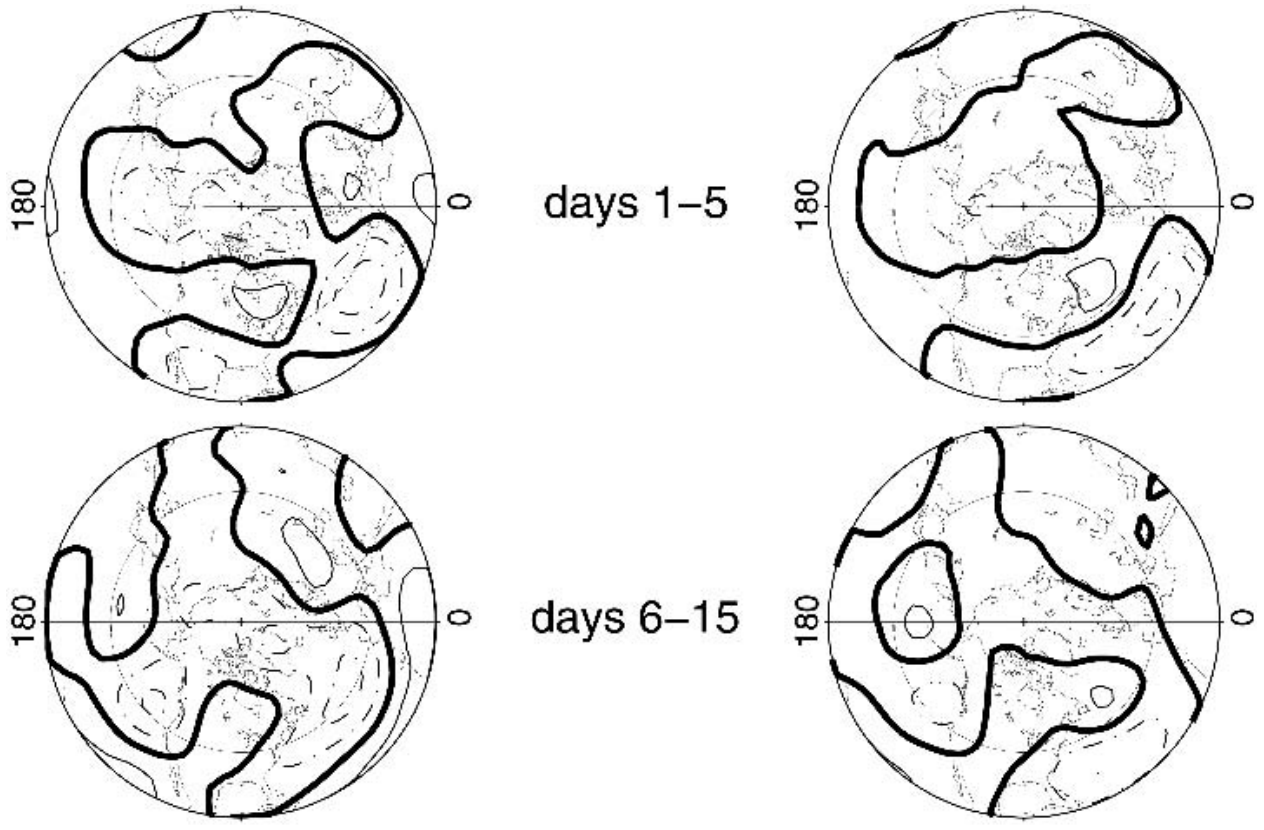

days $6-15$

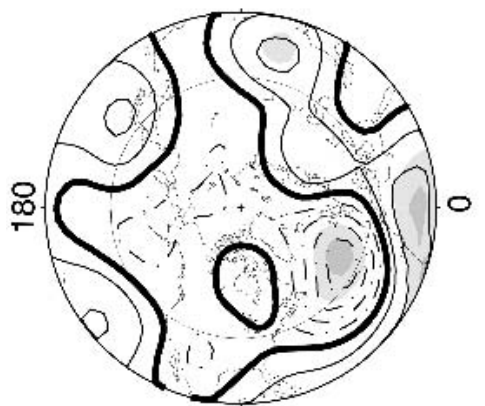

days $16-30$

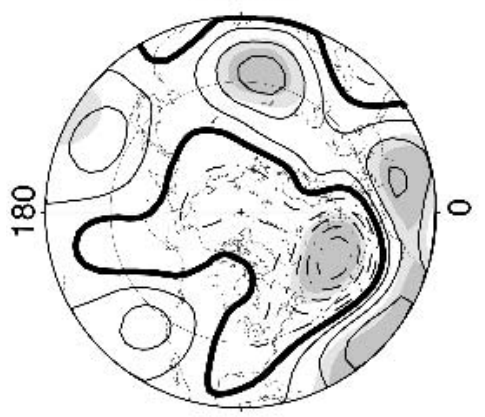

month 2
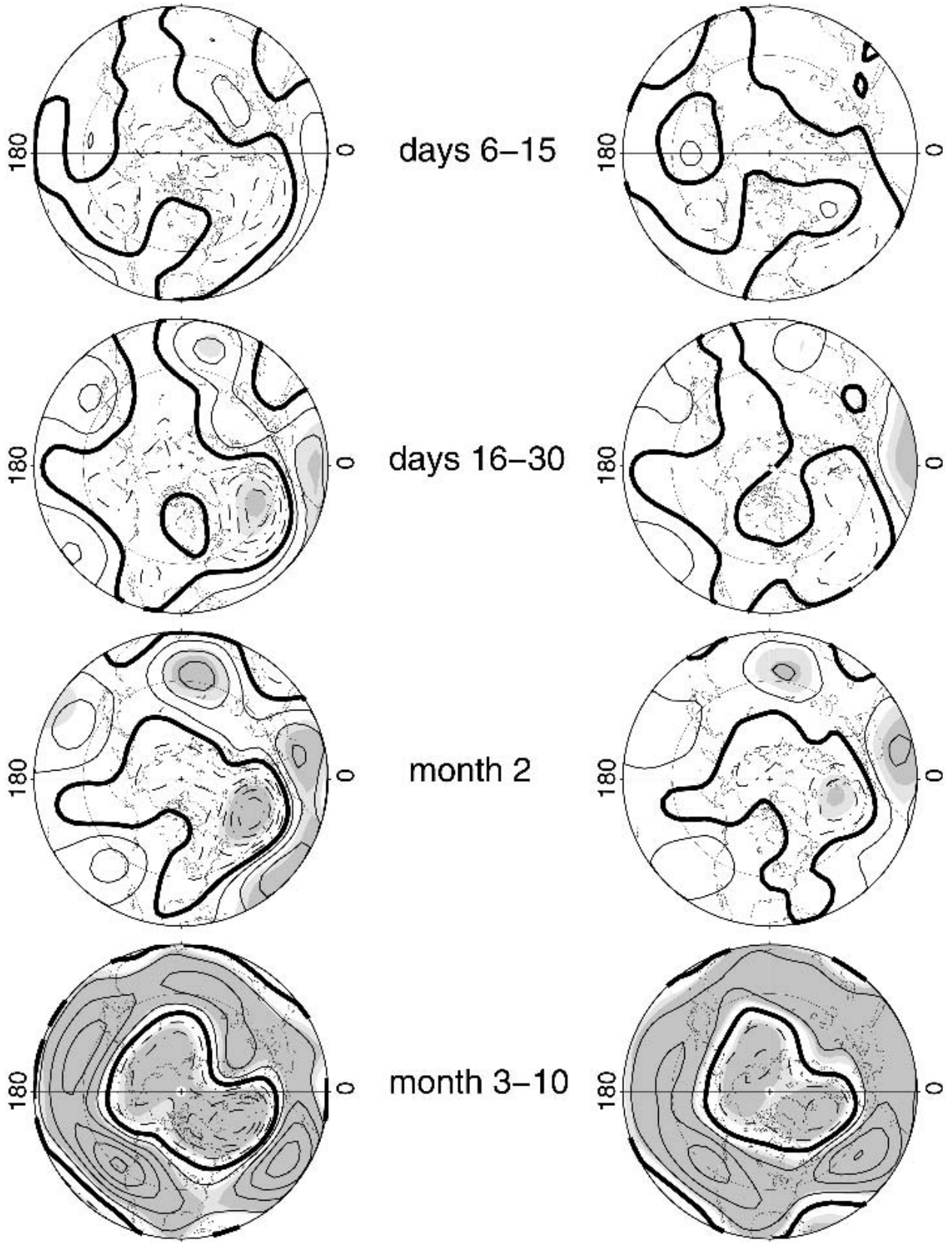

month $3-10$

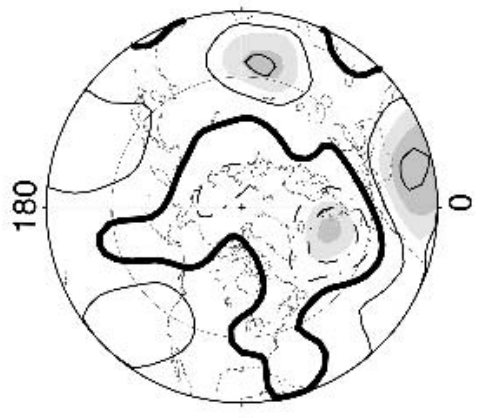

FIG. 13. Transient atmospheric response to EOF2 $\times(+3)$ at (left) 500 and (right) $800 \mathrm{mb}$. Time average intervals are indicated. The contour interval is $5 \mathrm{~m}$, otherwise same as in Fig. 5. 
frequency variability as well as the observed relationship between their cause and effect. The simplified QG dynamics has obviously some limitations, as evident in the deficiencies of the modeled storm track and lowfrequency variability. These biases could significantly affect the response and it is expected that some of our results, especially quantitative aspects, vary in more realistic models.

In a series of sensitivity experiments, the first two SST EOFs (with different amplitude and polarity) were prescribed as fixed anomalous boundary conditions for the atmospheric component. The transient response showed two distinct phases: first a baroclinic phase and then an equivalent barotropic one. Initially, as the unperturbed wind blows over the SST anomaly, the surface heat flux tends to strongly damp the SST anomaly, generating an anomalous diabatic heating of the lower atmosphere that forces a baroclinic response, with a trough at $800 \mathrm{mb}$ and a ridge at 500 and $200 \mathrm{mb}$ above and slightly downstream of a warm SST anomaly. This baroclinic phase primarily results from the thermal expansion of the air column in response to the diabatic heating, and is similar to that predicted by timeindependent linear models (Hoskins and Karoly 1981) and found in the initial response of AGCMs ( $\mathrm{Li}$ and Conil 2003). It was shown that the linear baroclinic response modifies the storm track and creates anomalous transient eddy fluxes that feedback on the largescale baroclinic response. At $500 \mathrm{mb}$, the heat and momentum eddy fluxes oppose each other, respectively, damping and reinforcing the initial response while, at $800 \mathrm{mb}$, both components contribute equally to damp it and then force a perturbation of the opposite sign. The net effect of the transient eddy fluxes is to barotropize the initial baroclinic response and then sustain the equivalent barotropic one. This confirms the scenario suggested by Peng and Whitaker (1999) and Peng et al. (2003), although they did not consider the eddy heat forcing. In our case, the heat component is as important as the momentum one in changing the initial baroclinic structure into an equivalent barotropic one. Unfortunately, we did not save the daily data that would allow us to determine if the heat forcing remains essential as the response approaches equilibrium. Others studies suggest that the eddy momentum flux is indeed dominant in sustaining the equilibrium response (e.g., Peng and Whitaker 1999). In fact, the asymmetric responses to opposite SST EOF1 polarities seem to be related to an asymmetric eddy momentum flux. This could indicate that the heat component does not play a critical role in determining the equilibrium response.

The sensitivity of the atmospheric response to the phase and amplitude of the SST anomaly was found to be similar for the two EOFs. For a given polarity of the SST anomaly, the atmospheric response varies linearly with its amplitude. The polarity of the response changes with that of the SST anomaly but there is a significant asymmetry in amplitude, as the atmosphere is more sensitive to an increase in the meridional SST gradient in the storm track region. The asymmetry may be due to an asymmetric transient eddy feedback or arise from a nonlinear self-interaction of the large-scale response as in Peng et al. (2003).

The SST anomalies considered here were forced by the main modes of atmospheric variability (the NAO for SST EOF1 and the EAP for SST EOF2) through anomalous surface heat flux and Ekman advection. In turn, the atmospheric equilibrium responses to these SST anomalies strongly projected on their respective atmospheric forcing pattern, which would result in a positive feedback. The positive feedback is stronger for the NAO as the response averages (over the two polarities and amplitudes) to $21 \%$ of the forcing amplitude at $500 \mathrm{mb}$ versus $16 \%$ for the EAP pattern. Although these estimates do not directly apply to the coupled system (e.g., Liu and Wu 2004), they are consistent with the differences between the coupled and uncoupled simulations since the coupling enhances the NAO variability by $14 \%$ versus $10 \%$ for the EAP. Furthermore, the NAO persistence increased from 2 to 2.8 months while the EAP one was not significantly changed. Finally, the larger positive feedback on the NAO, combined with the asymmetry of the response, can explain why the coupled minus uncoupled Z500 climatology showed a weak, but significant, positive NAO phase.

Although the anomalous heat flux associated to the atmospheric response tends to reinforce the SST anomaly, it is never large enough to reverse the strong heat flux damping initially caused by the introduction of the SST anomaly. The negative heat flux feedback only decreases in magnitude following the atmospheric buildup, but it remains negative up to equilibrium, thereby preventing an instability of the coupled system. A negative heat flux feedback is consistent with the observations (e.g., Frankignoul and Kestenare 2002), but contrasts with the sensitivity study of Peng et al. (2002) who observed a positive feedback at high latitudes. The larger sensitivity of the atmosphere to the SST EOF1 may be explained, in part, by the geographical variations of the heat flux feedback that is found larger above the dominant lobe of SST EOF1 than above that of SST EOF2. These geographical variations arise from the southward decrease of the Bowen ratio and the maximum surface wind speed found around $35^{\circ}-40^{\circ} \mathrm{N}$ and are consistent with the observations. Indeed, Frankignoul and Kestenare (2002) showed that, in winter, the negative heat flux feedback has a welldefined maximum around $35^{\circ}-45^{\circ} \mathrm{N}$ (see their Fig. 3).

However, this effect does not fully account for the differences in atmospheric sensitivity, and the transient eddy feedback probably contributes too. Branstator (1995) suggested that the dominant mode of lowfrequency variability is the one that can most efficiently modify the storm track in such a way that the anomalous eddy fluxes positively feed back upon it. Such a 
mechanism probably also applies when the atmospheric anomaly is initiated by a SST anomaly. Therefore, one expects that, in our model, a NAO-like atmospheric response to a SST anomaly is more strongly reinforced by the transient eddies than an EAP-like one.

An important result of this study is the long adjustment time of the atmosphere, which varies from 1 month for the weakest responses to up to 4 months for the largest NAO-like response, is significantly longer than the 10 days that are usually assumed. Although the longest adjustment time may be due in part to biases in the intrinsic NAO variability, the slow adjustment is consistent with the results of Kushnir and Lau (1992) and Hall et al. (2001b), and with the transient eddy feedback time scale that was estimated by Lau and Nath (1991) to range from a few days at the surface to 1-2 month at the tropopause.

It raises interesting questions about the relevance of the equilibrium response to a prescribed SST or heating anomaly. Considering the equilibrium response in perpetual conditions has often been justified by arguing that the atmospheric adjustment is much shorter than both the persistence of extratropical SST anomalies and the seasonal changes in the climatology. It now appears that the time scales are comparable. A more realistic assessment of the atmospheric response to SST anomalies should thus include two elements: 1) a two-way interaction where the SST anomaly is allowed to respond to air-sea exchanges and 2) seasonally varying conditions. In a coupled setup, it is excepted from our experiments that, because of the negative heat flux feedback, the SST anomaly significantly weakens over the adjustment time scale of the atmosphere. Rather unintuitively, this does not necessarily implies a weaker atmospheric response, as illustrated by $\mathrm{Liu}$ and $\mathrm{Wu}$ (2004) where the overestimation of the surface heat flux resulting from a prescribed SST anomaly eventually leads to a reduced atmospheric response compared to the coupled case. We do not know if such mechanisms apply here, however their study and ours agree in that a full coupling process need to be included. Concerning the second point, Peng et al. (1997) have already underscored the critical influence of climatological atmospheric state on the atmospheric response. Since the atmospheric response to SST anomaly may adjust slowly enough to feel the seasonal modulation, one might speculate that the seasonal variation could shut down a developing response or delay the development of a response until more "favorable" mean conditions are reached. Finally, the oceanic seasonal state may also play a role, in particular, the mixed layer depth variations that strongly influence the persistence of the SST anomaly.

Acknowledgments. This work was part of Ferreira's doctoral thesis at the University Pierre and Marie $\mathrm{Cu}$ rie. We are thankful to Dr. Fabio D'Andrea for providing the Marshall and Molteni (1993) model. We also thank three anonymous reviewers for their useful comments. Ferreira was supported by a bursary from the DGA-CNRS; support from the PNEDC, the Institute Universitaire de France, and the MIT-France Program is also acknowledged.

\section{REFERENCES}

Barsugli, J. J., and D. S. Battisti, 1998: The basic effects of atmosphere-ocean thermal coupling on midlatitude variability. $J$. Atmos. Sci., 55, 477-493.

Blackmon, M. L., 1976: A climatological spectral study of the 500 $\mathrm{mb}$ geopotential height of the Northern Hemisphere. J. Atmos. Sci., 33, 1607-1623.

Branstator, G., 1992: The maintenance of low-frequency atmospheric anomalies. J. Atmos. Sci., 49, 1924-1946.

_ 1995: Organization of storm track anomalies by recurring low-frequency circulation anomalies. J. Atmos. Sci., 52, 201226.

Cayan, D., 1992a: Variability of latent and sensible heat fluxes estimated using bulk formulae. Atmos.-Ocean, 22, 1-41.

- 1992b: Latent and sensible heat flux anomalies over the Northern Oceans: Driving the sea surface temperature. $J$. Phys. Oceanogr., 22, 859-881.

Czaja, A., and C. Frankignoul, 1999: Influence of the North Atlantic SST on the atmospheric circulation. Geophys. Res. Lett., 26, 2969-2972.

$\longrightarrow$, and - 2002: Observed impact of Atlantic SST anomalies on the North Atlantic oscillation. J. Climate, 15, 606-623.

D'Andrea, F., and Coauthors, 1998: Northern Hemisphere atmospheric blocking as simulated by 15 atmospheric general circulation models in the period 1979-1988. Climate Dyn., 14, 385-407.

_ , and R. Vautard, 2001: Extratropical low-frequency variability as a low dimensional problem. I: A simplified model. Quart. J. Roy. Meteor. Soc., 127, 1357-1375.

Ferreira, D., C. Frankignoul, and J. Marshall, 2001: Coupled ocean-atmosphere dynamics in a simple midlatitude climate model. J. Climate, 14, 3704-3723.

Frankignoul, C., 1985: Sea surface temperature anomalies, planetary waves and air-sea feedback in the middle latitudes. Rev. Geophys., 23, 357-390.

_ , and K. Hasselmann, 1977: Stochastic climate models. Part II: Application to sea-surface temperature anomalies and thermocline variability. Tellus, 29, 284-305.

- and E. Kestenare, 2002: The surface heat flux feedback. Part 1: Estimates from observations in the Atlantic and the North Pacific. Climate Dyn., 19, 633-647.

Hall, N., J. Derome, and H. Lin, 2001a: The extratropical signal generated by a midlatitude SST anomaly. Part I: Sensitivity at equilibrium. J. Climate, 14, 2035-2053.

- H. Lin, and J. Derome, 2001b: The extratropical signal generated by a midlatitude SST anomaly. Part II: Influence on seasonal forecasts. J. Climate, 14, 2696-2709.

Hoskins, B. J., and D. Karoly, 1981: The steady linear response of a spherical atmosphere to thermal and orographic forcing. $J$. Atmos. Sci., 38, 1179-1196.

Hurrel, J. W., and H. Van Loon, 1997: Decadal variations in climate associated with the North Atlantic Oscillation. Climatic Change, 36, 301-326.

Kushnir, Y., and N.-C. Lau, 1992: The general circulation model response to a North Pacific SST anomaly: Dependence on time scale and pattern polarity. J. Climate, 5, 271-283.

_ , and I. M. Held, 1996: Equilibrium atmospheric response to North Atlantic SST anomalies. J. Climate, 9, 1208-1220.

, W. A. Robinson, I. Bladé, N. Hall, S. Peng, and R. Sutton, 2002: Atmospheric GCM response to extratropical SST anomalies: Synthesis and evaluation. J. Climate, 15, 22332256. 
Lau, N.-C., and E. O. Holopainen, 1984: Transient eddy forcing of the time mean flow as identified by geopotential tendencies. J. Atmos. Sci., 41, 313-328.

_ , and M. J. Nath, 1991: Variability of the baroclinic and barotropic transient eddy forcing associated with monthly changes in the midlatitude storm tracks. J. Atmos. Sci., 48, 2589-2613.

Levitus, S., and T. Boyer, 1994: Temperature. Vol. 4, World Ocean Atlas 1994, NOAA Atlas NESDIS 4, $117 \mathrm{pp}$

Li, Z. X., and S. Conil, 2003: Transient response of an atmospheric GCM to North Atlantic SST anomalies. J. Climate, 16, 3993 3998.

Liu, Z., and L. Wu, 2004: Atmospheric response to North Pacific SST: The role of the ocean-atmosphere coupling. J. Climate, 17, 1859-1882.

Manabe, S., and R. J. Stouffer, 1996: Low-frequency variability of surface air temperature in a 1000-year integration of a coupled atmosphere-ocean-land surface model. J. Climate, 9, 376-393.

Marshall, J., and F. Molteni, 1993: Toward a dynamical understanding of planetary-scale flow regimes. J. Atmos. Sci., 50, 1792-1818.

Palmer, T. N., and Z. Sun, 1985: A modeling and observational study of the relationship between sea surface temperature in the northwest Atlantic and the atmospheric general circulation. Quart. J. Roy. Meteor. Soc., 111, 947-975.

Peng, S., and J. S. Whitaker, 1999: Mechanisms determining the atmospheric response to midlatitude SST anomalies. $J$. Climate, 12, 1393-1408.

- and W. A. Robinson, 2001: Relationship between the internal variability and the responses to an extratropical SST anomaly. J. Climate, 14, 2943-2959.

,-- , and M. P. Hoerling, 1997: The modeled atmospheric response to midlatitude SST anomalies and its dependence on the background circulation states. J. Climate, 10, 971-987. -, and S. Li, 2002: North Atlantic SST forcing of the NAO and relationships with intrinsic hemispheric variability Geophys. Res. Lett., 29, 1276, doi:10.1029/2001GL014043.

,-- , and — 2003: Mechanisms for the NAO responses to the North Atlantic SST tripole. J. Climate, 16, 1987-2004.

Rodwell, M. J., D. P. Rowell, and C. K. Folland, 1999: Oceanic forcing of the winter-time North Atlantic oscillation and European climate. Nature, 398, 320-323.

Saravanan, R., and J. C. McWilliams, 1998: Advective oceanatmosphere interaction: An analytical stochastic model with implications for decadal variability. J. Climate, 11, 165-188.

Wallace, J. M., and D. S. Gutzler, 1981: Teleconnections in the geopotential height field during the Northern Hemisphere winter. Mon. Wea. Rev., 109, 784-812.

Walter, K., U. Luksch, and K. Fraedrich, 2001: A response climatology of idealized midlatitude thermal forcing experiments with and without a storm track. J. Climate, 14, 467-484. 